\title{
Amyloid Precursor Protein Is a Biomarker for Transformed Human Pluripotent Stem Cells
}

\author{
Vivek Venkataramani, ${ }^{, \dagger}$ Knut Thiele, ${ }^{\neq}$ \\ Carl Ludwig Behnes, ${ }^{\ddagger}$ Gerald G. Wulf, ${ }^{\dagger}$ \\ Paul Thelen, ${ }^{\S}$ Lennart Opitz, ${ }^{\natural}$ \\ Gabriella Salinas-Riester," Oliver Wirths, * \\ Thomas A. Bayer, ${ }^{*}$ and Stefan Schweyer ${ }^{\ddagger}$ \\ From the Division of Molecular Psychiatry," Department of \\ Psychiatry, and the Departments of Hematology and Oncology, \\ Pathology, ${ }^{\ddagger}$ and Urology, ${ }^{\S}$ and the DNA Microarray Facility, ${ }^{\top}$ \\ University Medicine Goettingen, Goettingen, Germany
}

Increasing evidence suggests an important function of the $\beta$-amyloid precursor protein (APP) in malignant disease in humans; however, the biological basis for this evidence is not well understood at present. To understand the role of APP in transformed pluripotent stem cells, we studied its expression levels in human testicular germ cell tumors using patient tissues, model cell lines, and an established xenograft mouse model. In the present study, we demonstrate the cooperative expression of APP with prominent pluripotency-related genes such as Sox 2, NANOG, and POU5F1 (Oct3/4). The closest homologue family member, APLP2, showed no correlation to these stem cell factors. In addition, treatment with histone deacetylase (HDAC) inhibitors suppressed the levels of APP and stem cell markers. Loss of pluripotency, either spontaneously or as a consequence of treatment with an HDAC inhibitor, was accompanied by decreased APP protein levels both in vitro and in vivo. These observations suggest that APP represents a novel and specific biomarker in human transformed pluripotent stem cells that can be selectively modulated by HDAC inhibitors. (Am J Pathol 2012, 180: 1636-1652; DOI: 10.1016/j.ajpath.2011.12.015)

The subsets of testicular germ cell tumors (TGCT) occur predominantly in young men between the ages of 15 and 35 years. ${ }^{1}$ In contrast to other common malignant lesions, the precursors of TGCT are primordial germ cells that escape the physiologic process of maturation and, consequently, are at risk for malignant transformation. ${ }^{2}$ The group of TGCT can be subdivided into the homogeneous group of seminomas (SE) and the heterogeneous group of non-SE including the undifferentiated embryonal carcinomas (EC), which are composed primarily of pluripotent stem cells. A differentiated subset comprises yolk sac tumors (YST) and choriocarcinomas (CC), consisting primarily of extra-embryonal differentiated tissues and teratomas (TE), which are composed primarily of mature somatic elements derived from all three germ cell layers. ${ }^{2}$ The various histopathologic features of TGCT are reflected in part in the physiologic processes of embryonic development and cell differentiation. ${ }^{3}$ Therefore, as a pathobiological concept, EC cells are considered to be the malignant counterpart of human embryonic stem cells. The mechanisms and guidance factors that control or contribute to cell differentiation, pluripotency, and selfrenewal have not been fully elucidated. However, it is widely accepted that stem cell genes such as the transcription factors octamer (Oct)3/4 (approved symbol, POU5F1), Sox2, and the master transcription regulator NANOG are predominantly expressed in pluripotent cell types, acting together to establish embryonic stem cell identity. A recent report has revealed striking parallels between overexpression of stemness genes and histologically poorly differentiated tumors. This study also indicated that the stem cell signature is associated with an aggressive tumor behavior and may serve as a powerful predictor of poor clinical outcome. ${ }^{4}$

A growing body of evidence supports the critical involvement of the $\beta$-amyloid precursor protein (APP) and its derived $\beta$-amyloid peptides $(A \beta)$ in Alzheimer's disease. ${ }^{5}$ APP is an evolutionary highly conserved glycoprotein consisting of a large $\mathrm{N}$-terminal extracellular domain (which shows similarities to cystein-rich growth factors), a hydrophobic transmembrane, and a short intracellular C-terminal domain. ${ }^{6}$ APP can be processed by two independent proteolytic pathways. The key event leading to

Supported by grants from Deutsche Krebshilfe (S.S. and P.T.). Valpromide was provided by Katwijik Chemie BV.

Accepted for publication December 6, 2011.

Supplemental material for this article can be found on http://ajp. amjpathol.org or at doi: 10.1016/j.ajpath.2011.12.015

Address reprint requests to Vivek Venkataramani, M.D., Department of Hematology and Oncology, University Medicine Goettingen, RobertKoch-Str 40, 37075 Goettingen, Germany. E-mail: ramani@med.unigoettingen.de. 
senile plaques in the brain in patients with Alzheimer's disease is initiated by $\beta$-secretase cleavage, subsequently followed by $\gamma$-secretase cleavage, generating $A \beta$ peptides. However, the predominant processing route of APP is mediated by $\alpha$ - and $\gamma$-secretases, releasing SAPP $\alpha{ }^{7}$ In addition to APP, the small gene family includes two other type I transmembrane proteins: amyloid $\beta$ precursor-like protein 1 (APLP1) and amyloid $\beta$ precursor-like protein 2 (APLP2). In contrast to APLP1, which is predominantly expressed in neuronal tissue, APLP2 is expressed ubiquitously. ${ }^{8}$ Several studies have shown that APP and its secreted form, $\operatorname{SAPP} \alpha$, perform a wide array of cellular activities including cell adhesion, migration, and neurite outgrowth. ${ }^{9}$ The groundbreaking work of Saitoh et $\mathrm{al}^{10}$ established that APP and its secreted Nterminal counterpart SAPP $\alpha$ possess growth-promoting activity and that down-regulation of APP in rat fibroblasts directly affects cell growth. We and others have found complementary evidence of the causal involvement of APP as a potent tumor growth factor in the pathogenesis of several somatic tissue cancers. ${ }^{11,12}$ The metabolism, trafficking, and processing of APP are highly coordinated processes. Like other secreted proteins, APP is folded and glycosylated in the endoplasmic reticulum (ER), translocated to the Golgi apparatus, and subsequently transported to the plasma membrane, where secretase cleavage occurs. Post-translational modifications, in particular O-linked oligosaccharides, have an important role in sorting, processing, and secretion of APP. ${ }^{13}$ It has been suggested that interruption of the maturation process or improperly glycosylated APP leads to its retrotranslocation to the cytosol for subsequent degradation by the ubiquitin-proteasome system. ${ }^{14,15}$

In the present study, we characterized the expression profile of APP in a panel of 173 human TGCT of different histologic origin. Furthermore, we revealed that histone deacetylase (HDAC) inhibitors effectively induced EC cell differentiation, accompanied by down-regulated stem cell signature and APP protein levels. On the basis of this observation, we tested these in vitro findings in a physiologically relevant in vivo setting and evaluated HDAC inhibitormediated alterations on endogenous APP protein levels and tumor growth in an established xenograft mouse model. In line with a recent study, stem cell genes were transcriptionally repressed during treatment with several HDAC inhibitors. ${ }^{16}$ In contrast, APP protein levels were suppressed through a post-translational mechanism. The objective of the study was to examine the role of APP in transformed pluripotent stem cells and to obtain a better understanding of the involvement of post-translational mechanisms that regulate APP metabolism during spontaneous and pharmacologically induced differentiation.

\section{Materials and Methods}

\section{Reagents}

Valproic acid (VPA), trichostatin A (TSA), and apicidin were purchased from Sigma-Aldrich (Munich, Germany). VPA was prepared in sterile aqua ad injectionem and added to the final concentrations as indicated. TSA (5 $\mathrm{mmol} / \mathrm{L}$ stock solution) and apicidin (1 mmol/L stock solution) were dissolved in dimethyl sulfoxide (DMSO; Sigma-Aldrich). Valpromide (VPM) was a kind gift from Katwijk Chemie B.V. (Katwijk, Netherlands). A stock solution of VPM was prepared at a concentration of 2.5 $\mathrm{mmol} / \mathrm{L}$ in DMSO. N-acetyl-leu-leu-norleucinal (ALLN; Calbiochem, San Diego, CA) was dissolved in DMSO and used at a final concentration of $50 \mu \mathrm{mol} / \mathrm{L}$. In no experiments did the final concentration of DMSO exceed $0.2 \%$. Recombinant human APP/protease nexin II peptide (rh sAPP; R\&D Systems, Inc., Minneapolis, MN) was dissolved in sterile deionized water.

\section{Antibodies Used in Immunohistochemistry}

For immunohistochemistry, the following antibodies were used: APP antibody (22C11, 1:600; Millipore Corp., Billerica, MA), APLP2 (D2-II, 1:1000; Calbiochem), GRP78/ $\operatorname{BiP}(a b 21685,1: 300 ;$ Abcam, Inc., Cambridge, MA), Oct3/4 (C-10, 1:50; Santa Cruz Biotechnology, Inc., Santa Cruz, CA), NANOG (H-155, 1:200; Santa Cruz Biotechnology), Sox2 (AF2018, 1:200; R\&D Systems), and Ki-67 (MIB-1, 1:50; Dako Corp., Carpinteria, CA).

\section{Antibodies Used in Western Blot Analysis}

Unless otherwise indicated, the monoclonal APP/A $\beta$ antibody W-02 (1:5000; The Genetics Co., Inc., Zurich, Switzerland) was used to detect full-length APP in cell lysates and SAPP $\alpha$ in culture media. The following antibodies were used: APP antibody (22C11, 1:1000-1:5000) and anti-acetyl-histone $\mathrm{H} 4$ (catalog No. 06-866, 1:2000) (both from Millipore); sAPP $\beta$ (lot No. OH-708, $2 \mu \mathrm{g} / \mathrm{mL}$; IBL International $\mathrm{GmbH}$, Hamburg, Germany); APLP2 (D2-II, 1:5000; Calbiochem); GRP78/BiP (C50B12, 1:1000), HSP70 (C45G5, 1:500), and caspase-3 (8G10, 1:1000) (all three from Cell Signaling Technology, Inc., Beverly, MA); NANOG (H-155, 1:200) and Oct-3/4 (C-20, 1:200) (both from Santa Cruz Biotechnology); Sox2 (ab59776, 1:1000; Abcam); pan-CK (AE1/AE3, 1:500; Dako); $\beta$-actin (AC-74, 1:5000; Sigma-Aldrich); and AFP (EP1016Y, 1:5000; Epitomics, Inc., Burlingame, CA).

\section{Cell Culture}

The following human EC cell lines were used: NTera-2/ c1.D1 (CRL-1973) and NCCIT (CRL-2073) (both from American Type Culture Collection, Manassas, VA). The human EC stem cell line NTera-2/c1.D1 cell line (referred to as NTera-2) is a clonal EC subline of TERA-2. ${ }^{17}$ The NCCIT cell line is a mediastinal mixed human TGCT cell line. ${ }^{18}$ The human SE cell line TCam- $2^{19}$ was derived from a patient with SE. All cell lines were cultured in RPMI 1640 medium (PAN-Biotech $\mathrm{GmbH}$, Aidenbach, Germany) supplemented with $10 \%$ fetal calf serum (Biochrom AG, Berlin, Germany), 2 mmol/L L-glutamine, and 1\% penicillin-streptomycin (both from PAN-Biotech. The medium was changed every 2 to 3 days, and cells were passaged using $0.025 \%$ trypsin-EDTA (PAN-Biotech) every 3 to 4 days. All cell lines were cultured at $37^{\circ} \mathrm{C}$ in a humidified 
atmosphere of $5 \% \mathrm{CO}_{2}$. A stably transfected SH-SY5Y neuroblastoma cell line overexpressing APP695 $5_{w t}$ and a mock cell line expressing the empty pCEP4 vector were cultured as previously described. ${ }^{2}$ Similarly, COS-7 cells were either stably transfected with pCEP-APP695 (Cos APP $695_{w t}$ ) or with the pCEP4 vector alone (mock), and were cultured in Dulbecco's modified Eagle's medium supplemented with 10\% fetal calf serum, $2 \mathrm{mmol} / \mathrm{L}$ L-glutamine, and $1 \%$ penicillin-streptomycin. $\mathrm{CHO}$ (Chinese hamster ovary) cells stably transfected with cDNA encoding the 751 isoform of APP (APP751 wt) were used, and parental $\mathrm{CHO}$ cells served as a control. Both cell lines were cultured as previously described. ${ }^{20}$

\section{Patients and Tissue Samples}

All tumor samples were obtained from patients who had not received chemotherapeutic, radiotherapeutic, or immunomodulatory treatment before surgery. From 2005 to 2009, 173 patients underwent orchiectomy because of testicular cancer at the Department of Urology of the University Medicine Goettingen (Goettingen, Germany). Mean (SD) patient age at surgery was 36 (8) years. Ethical approval for the study was obtained from the Ethics Committee of the University of Goettingen for the use of human material. Histologic classification (tumor type and grade of malignancy) was performed according to the current classification system of the World Health Organization. Primary TGCT included 117 pure TGCT (96 SE, 15 EC, 3 YST, and 3 TE) and 56 mixed TGCT including areas of $24 \mathrm{SE}, 38 \mathrm{EC}, 5$ YST, $6 \mathrm{CC}$, and 26 TE. In addition, we examined randomly selected normal testicular tissue specimens from eight different individuals. Tissue from each TGCT was immediately fixed in 10\% formalin for 24 hours, embedded in paraffin, and processed for histologic analysis and immunohistochemistry. All slides were re-evaluated, and the diagnosis was approved independently by two experienced pathologists (C.L.B. and S.S.).

\section{Tissue Microarray}

Formalin-fixed, paraffin-embedded tissue blocks from orchiectomy specimens were used for tissue microarray construction. For each TGCT, three to five representative areas rich in tumor cells were identified via light microscopic examination and marked on H\&E-stained sections. Three to 15 cores measuring $0.1 \mathrm{~cm}$ in diameter were taken from the donor paraffin tissue blocks of each case and were arranged in a recipient paraffin tissue array block by using a manual tissue array (MTA-1; Alphelys SAS, Plaisir, France). All cases were arranged in 17 tissue microarray recipient paraffin blocks.

\section{Immunohistochemistry of Paraffin Sections}

Human and mouse tissue was processed as described previously. ${ }^{12}$ Immunohistochemical reactions were performed on 4- $\mu \mathrm{m}$ paraffin-embedded sections. The sections were deparaffinized, rehydrated, subjected to antigen retrieval, and incubated with the indicated primary antibodies. Sections were subsequently incubated with biotinylated anti-goat immunoglobulins or biotinylated secondary antibodies using a REAL Detection System (LSAB + kit; Dako). The signals were visualized using a REAL Streptavidin Alkaline Phosphatase kit (Dako). All samples were counterstained with Meyer's hematoxylin, mounted in super mount medium, and analyzed via light microscopy. Controls were stained as above but with omission of primary or secondary antibodies. A semiquantitative immunostaining score was obtained by association of the area fraction of labeled cells with a staining intensity based on visual qualitative observation. All samples were stained and analyzed in triplicate.

\section{Cellular Differentiation Assays}

Indications for differentiation and inhibition of cell growth were obtained by analyzing cellular proliferation rate, cell architecture, and expression of lineage-specific differentiation markers. Reduction of proliferation was shown in human EC cell lines NCCIT and NTera-2. Cell growth was measured using a colorimetric cell proliferation assay (CellTiter 96 Aqueous One Solution Assay (MTS assay; Promega $\mathrm{GmbH}$, Mannheim, Germany) according to the manufacturer's protocol, as described previously ${ }^{12}$. In brief, $5 \times 10^{3}$ cells per well were plated in $100 \mu \mathrm{L}$ cell medium in a 96-well plate and allowed to settle for 24 hours. The cells were than treated for 24 hours with medium containing VPA, VPM, TSA, or apicidin. Cell growth was then determined using $20 \mu \mathrm{L}$ dye solution, and incubated for an additional 2 hours at $37^{\circ} \mathrm{C}, 5 \% \mathrm{CO}_{2}$. For detection, an enzyme-linked immunosorbent assay reader ( $\mu$ Quant Microplate Spectrophotometer; BioTek Instruments $\mathrm{GmbH}$, Bad Friedrichshall, Germany) was used to measure the absorbance at $490 \mathrm{~nm}$ and a reference wavelength of $650 \mathrm{~nm}$. All experiments were performed six times, and data are given as relative number of viable cells in each well. For immunocytochemistry, cells were grown on four-well chamber slides (Lab-Tek; Thermo Fisher Scientific, Inc., Rockford, IL). After 24-hour treatment with either VPA or apicidin at indicated concentrations, cells were fixed with ice-cold methanol and permeabilized with $0.5 \%$ Triton X-100 in PBS, blocked with $10 \%$ fetal calf serum in PBS containing $4 \%(w / v)$ dry skim milk powder, and incubated overnight with primary antibodies: $\beta$-actin (1:1000; Sigma-Aldrich) and 23850 (1: 250 to $1: 500, N$-terminal APP antibody against APP residues 18-491). Visualization was achieved by using Alexa Fluor 488/568-labeled anti-mouse or anti-rabbit IgG secondary antibodies (Molecular Probes, Inc., Eugene, OR).

\section{Cytotoxcicity Assay}

Cell membrane integrity was analyzed by measuring the release of lactate dehydrogenase (LDH) using the CytoTox 96 non-radioactive kit (Promega). Cells were plated in a 96-well plate at a density of $5 \times 10^{3}$ in medium for 24 hours. Thereafter, cells were incubated for 24 hours in the presence of the indicated compounds. At 45 minutes before supernatants were harvested, untreated cells were incubated in the presence of lysis solution containing Triton $\mathrm{X}-100$ to determine maximum $\mathrm{LDH}$ release 
(positive control). The 96-well plates were centrifuged at $250 \times g$ for 4 minutes. Then $50 \mu \mathrm{L}$ medium was removed from each well and added to $50 \mu \mathrm{L}$ reconstituted substrate mix for 30 minutes in the dark at room temperature. The enzymatic reaction was terminated by adding $50 \mu \mathrm{L}$ Stop Solution. Absorbance was measured at $490 \mathrm{~nm}$ using a $\mu$ Quant Microplate Spectrophotometer. All experiments were performed six times. After the background value was subtracted, results were expressed as a percentage of LDH released compared with the maximum $\mathrm{LDH}$ release [Cytotoxcicity (\%)].

\section{Knockdown of APP Using Small Interfering RNA}

NTera-2 cells were grown in six-well plates to approximately $30 \%$ to $50 \%$ confluence. Two hours before transfection, the complete medium was withdrawn and replaced with antibiotic-free medium. Two different small interfering RNA (siRNA) duplexes targeting APP were used (Silencer Select Validated siRNA; Ambion, Inc., Austin, TX): APP siRNA 1, s1500, sense sequence 5'CAAGGAUCAGUUACGGAAATT-3' and antisense sequence 5'-UUCCGUAACUGAUCCUUGGT-3', and APP siRNA 2, s1501, sense sequence 5'-GACUGAACAUGCACAUGATT-3' and antisense sequence 5'-UUCAUGUGCAUGUUCAGUCTG-3'). Equimolar random siRNA (Silencer Select Negative Control; Ambion) served as negative control targeted to a scrambled sequence. Cells treated only with Lipofectamine 2000 (Invitrogen Corp., Carlsbad, CA) were used as an additional control. Lipofectamine 2000 and Opti-MEM I Reduced Serum Medium (Invitrogen Corp.) were used to transfect cells according to the manufacturer's protocol at a final concentration of $50 \mathrm{nmol} / \mathrm{L}$. Transfection was performed for 6 hours. Thereafter, transfection medium was replaced with serum-free medium, and the transfected cells were incubated for another 96 hours.

\section{Protein Isolation and Western Blot Analysis}

NTera-2 and NCCIT cells were harvested using a rubber policeman and lysed in buffer containing $50 \mathrm{mmol} / \mathrm{L}$ Tris, $150 \mathrm{mmol} / \mathrm{L} \mathrm{NaCl}, 1 \%$ Nonidet P-40, $1 \%$ Triton X-100, and $2 \mathrm{mmol} / \mathrm{L}$ EDTA ( $\mathrm{pH} 7.5)$ supplemented with $1 \times$ complete protease inhibitor mixture (Roche Applied Science, Mannheim, Germany) for 30 minutes at $4^{\circ} \mathrm{C}$. Cell lysates were centrifuged at $5000 \mathrm{rpm}$ for 10 minutes at $4^{\circ} \mathrm{C}$. For analysis of tumor xenografts, tumor pieces were homogenized using a Dounce homogenizer in extraction buffer containing $120 \mathrm{mmol} / \mathrm{L} \mathrm{NaCl}$ and $50 \mathrm{mmol} / \mathrm{L}$ Tris $(\mathrm{pH} \mathrm{8.0)}$ supplemented with complete protease inhibitor, and subsequently were centrifuged at $17000 \mathrm{rpm}$ for 20 minutes at $4^{\circ} \mathrm{C}$. The resulting pellets were resuspended in lysis buffer as described above, sonified, and centrifuged for 15 minutes. Cell lysates were further treated with nuclease (benzonase, $50 \mathrm{U} / \mathrm{mL}$ ) for 15 minutes at $4^{\circ} \mathrm{C}$ and centrifuged at 10,000 rpm for 2 minutes. Ten micrograms to $25 \mu \mathrm{g}$ protein was loaded per well, and proteins were separated on precast $4 \%$ to $12 \%$ Vario-Gels (Anamed Elektrophorese $\mathrm{GmbH}$, Groß-Bieberau, Germany) and transferred to nitrocellulose membranes (GE Healthcare,
Munich, Germany). Membranes were blocked for 1 hour in TBS-T [0.1 mmol/L Tris (pH 8.0), $1.5 \mathrm{mmol} / \mathrm{L} \mathrm{NaCl}$, and $0.5 \%$ Tween-20] containing 10\% (w/v) dry skim milk powder, and subsequently were incubated with the indicated antibodies overnight at $4^{\circ} \mathrm{C}$. For detection, membranes were incubated with the appropriate secondary antibody conjugated to horseradish peroxidase (Dako), and blots were visualized using enhanced chemiluminescence. For detection of SAPP, conditioned culture medium was collected and centrifuged at $14,000 \times g$ for 2 minutes at $4^{\circ} \mathrm{C}$ to remove detached cells. Subsequently, $2 \mathrm{~mL}$ supernatant was concentrated using centrifugal filter devices (Amicon Ultra-4 50K; Millipore) at $4000 \times g$ for 5 minutes. For quantification of relative protein levels, $x$-ray films (Hyperfilm EC; Amersham Biosciences, GE Healthcare, Piscataway, NJ) were scanned, and densitometric analysis was performed using ImageJ software (version 1.410; National Institutes of Health, Bethesda, MD).

\section{RNA Isolation and Quantitative RT-PCR}

Total cellular RNA was extracted from pelleted cells using a Mini RNA Isolation II Kit (Zymo Research Europe $\mathrm{GmbH}$, Freiburg, Germany). RNA integrity number and quantity of isolated RNA were measured using an Agilent Bioanalyzer 2100 on an RNA 6000 Nano LabChip Kit (Agilent Technologies Deutschland $\mathrm{GmbH}$, Waldbronn, Germany). Reverse transcription of total cellular RNA was performed using an Omniscript RT Kit (Qiagen $\mathrm{GmbH}$, Hilden, Germany). Quantitative PCR and melting curve analysis were performed in triplicate using a MyiQ-iCycler and corresponding software and SsoFast EvaGreen Supermix (all from Bio-Rad Laboratories $\mathrm{GmbH}$, Munich, Germany). To amplify NANOG, Oct-3/4 (POU5F1), Sox2, AFP and ARP, the following primer pairs were used: NANOG, forward 5'-GCAGGTTGAAGTGAACAGCA-3' and reverse 5'-ATCTGCTGGAGGCTGAGGTA-3'; Oct-3/4 (POU5F1), forward 5'-AGAAGGATGTGGTCCGAGTG-3' and reverse 5'-GTGAAGTGAGGGCTCCAATA-3'; Sox2, forward 5'-CAAGATGCACAACTCGGAGA-3' and reverse 5'-CTCCGGGAAGCGTGTACTTA-3'; AFP, forward 5'-AGCTTGGTGGTGGATGAAAC-3' and reverse 5'CCCTCTTCAGCAAAGCAGAC-3'; ARP, forward 5'CGACCTGGAAGTCCAACTAC-3' and reverse 5'-ATCTGCTGCATCTGCTTG-3'. Gene-specific oligonucleotide primers for human APP and GRP78 were purchased as validated primer sets (QuantiTect Primer Assays; Qiagen). ${ }^{12}$ Relative mRNA abundance was determined from standard curves run with each experiment. Gene expression was normalized using human acidic ribosomal protein (housekeeping gene) in each sample to standardize the results.

\section{Microarray Analysis and Statistical Evaluation}

Sample pairs with comparable RNA integrity number were selected for microarray analysis. Sample labeling with Cy5 and Cy3 from $1 \mu \mathrm{g}$ total RNA was performed using the Agilent 2-Color Low RNA Input Linear Amp Kit PLUS (Agilent Technologies) according to the manufacturer's protocols. Quantity and Cy-dye incorporation rates 
of the generated target material were assessed using a NanoDrop ND-100. Cy3- and Cy5-labeled cRNA fragments, respectively, were hybridized to $44 \mathrm{~K}$ Human Whole Genome Microarrays (Agilent Technologies) at 10 rpm at $65^{\circ} \mathrm{C}$ for 17 hours per the two-color microarraybased gene expression analysis version 5.5 protocol (Agilent Technologies). Post-processing washes were performed according to the SSPE protocol (version 2.1; Agilent Technologies), followed by immediate scanning using a microarray scanner (part No. G2505B; Agilent Technologies). Intensity data were extracted using Feature Extraction software (version 9.5, Agilent Technologies). The microarray data analysis was performed as described by Opitz et $a^{21}$ with the following modification: data were normalized using loess normalization. A custom PCR array (SuperArray; Quiagen) was used to simultaneously examine the mRNA levels of several genes according to the manufacturer's protocol.

\section{Mouse Tumor Xenografts and in Vivo Treatment Protocol}

Six-week-old male athymic nude (BALB/c-nu) mice were purchased from Charles River Germany (Sulzfeld, Germany). For acclimatization, mice were maintained for 2 weeks in standard cages with air filter hoods, with free access to food and water. Subsequently, all animals received an s.c. inoculation of $1 \times 10^{6}$ exponentially growing NTera-2 cells resuspended in $100 \mu \mathrm{L}$ PBS mixed with $100 \mu \mathrm{L}$ Matrigel (Becton Dickinson GmbH, Heidelberg, Germany) on the dorsal portion of the forelegs via a 26-gauge needle. Thereafter, animals were divided into three groups: control group $(n=15)$, prophylaxis group $(n=15)$, and therapy group $(n=15)$. The prophylaxis group received $400 \mathrm{mg} / \mathrm{kg} / \mathrm{d}$ VPA (Orfiril; Desitin Arzneimittel $\mathrm{GmbH}$, Hamburg, Germany) in the drinking water at 4 days after tumor inoculation; the therapy group received $400 \mathrm{mg} / \mathrm{kg} / \mathrm{d}$ VPA in drinking water started after subcutaneous tumors were palpable; and the control group received only drinking water. The weight of the mice and their food intake were determined twice a week, and with use of calipers, subcutaneous tumors were measured once a week. Tumor volume was calculated using the formula (Large diameter $) \times(\text { Smaller diameter })^{2} \times 0.5$, as described previously. ${ }^{22}$ After 75 days, animals were sacrificed via a $\mathrm{CO}_{2}$ overdose. Tumors were excised and halved. Half of the tumor was snap frozen on dry ice and stored at $-80^{\circ} \mathrm{C}$ until required for Western blot analysis, and the other half was fixed in 10\% buffered formalin and embedded in paraffin. All experiments were performed according to protocols approved by the local animal protection committee (reference No. 33.11.42502-04-058/07).

\section{Statistical Analysis and Software}

Statistical differences were evaluated using one-way or two-way analysis of variance followed by Bonferroni post hoc analysis or the unpaired Student's $t$-test, as indicated. Data are given as mean (SEM). All statistics were calculated using Prism software (version 5.00; GraphPad
Software, Inc., San Diego, CA). Statistical differences were considered significant as stated in the text. Symyx Draw (version 3.2.NET; Symyx Technologies, Inc., Santa Clara, CA) was used for the structure formula.

\section{Results}

\section{Immunohistochemical Detection of APP Correlates with the Stem Cell Signature in Pluripotent Germ Cell Tumors}

To elucidate the expression profiles of APP in testicular cancer, we examined 117 cases of pure TGCT and 56 cases of mixed TGCT (composed of all of the abovementioned subtypes). APP was highly expressed in undifferentiated SE and EC, and strongly correlated with the amount of the well-established pluripotency genes Sox2, NANOG, and POU5F1 (Oct3/4). In agreement with previous studies, the transcription factor Sox2 was uniformly expressed in EC, whereas SE demonstrated a lack of immunostaining (see Supplemental Figure S1 at $h t t p: / /$ ajp.amjpathol.org). ${ }^{23}$ Differentiated histologic cohorts, comprising YST, CC, and TE, exhibited only focal expression or were completely negative for APP and the stem cell signature. Despite these differences in APP expression, APLP2, the closest homologue to APP, was continuously expressed in all TGCT subgroups. Of note, APLP2 expression in mature TE was predominantly observed in epithelial structures (Figure 1A). Semiquantification of APP immunostaining using a score index revealed a significant difference of APP between the pluripotent cohort (SE and EC) and the more differentiated subtypes (YST, $\mathrm{CC}$, and TE) (Figure 1B). No statistically significant differences were observed in APLP2 immunostaining score over all TGCT subtypes (Figure 1C). We also examined the expression of APP and APLP2 in testicular tissue in healthy adult controls. APP was expressed at low levels, and only a few cells near the basement membrane, likely immature spermatogonia, contained low to moderate APP expression. In contrast, nearly all cell layers were intensely immunopositive for APLP2 (see Supplemental Figure S2 at $h$ ttp://ajp.amjpathol.org). To evaluate the relationship between APP expression and stem cell signature in vitro, we analyzed the SE cell line TCam-2 and EC cell lines NCCIT and NTera-2. These well-characterized cell lines express typical features of human TGCT. ${ }^{17-19}$ All three cell lines expressed APP and the stem cell marker NANOG and Oct-3/4. Consistent with the SE-like nature of TCam-2, Sox2 protein could not be detected. ${ }^{19}$ Compared with the other cell lines, the highest levels of APP were observed in human NTera-2 cells (Figure 1, D and $\mathrm{E})$.

\section{Transcriptional Modulation by HDAC Inhibition Is Associated with Cell Differentiation and Growth Inhibition}

HDAC inhibition causes increased histone acetylation, leading to coordinated changes in gene transcription. ${ }^{24}$ 


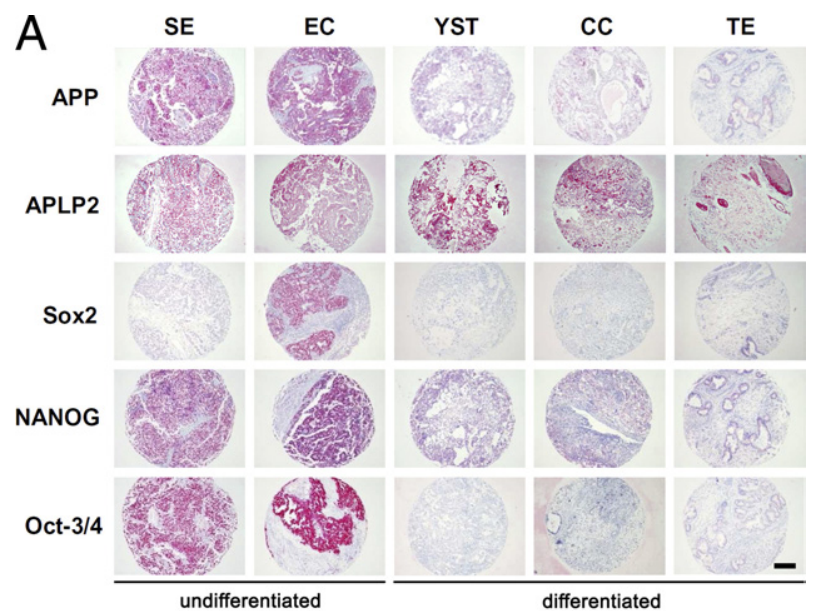

B

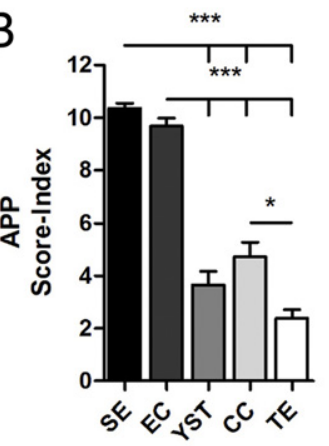

C
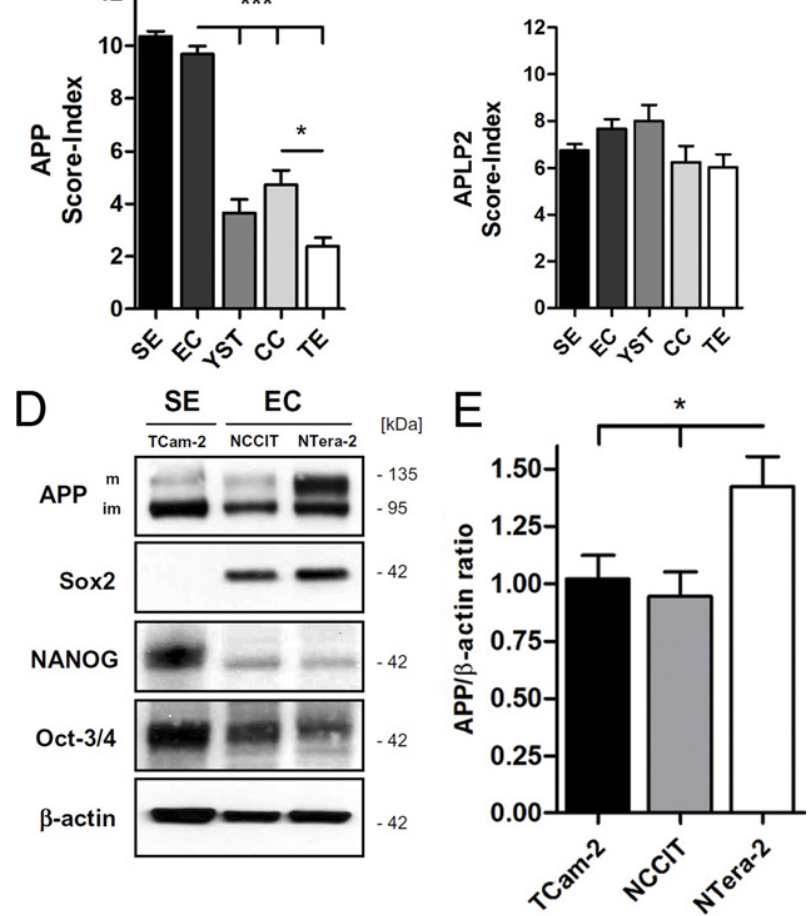

Figure 1. Correlation between APP and the stem cell signature in pluripotent germ cell tumors. A: Representative sections demonstrating expression of APP, APLP2, and the stem cell markers Sox 2 , Oct-3/4, and NANOG in various types of TGCT. B: Immunohistochemical analyses were performed on tissue microarrays containing 117 pure and 65 mixed TGCT. Statistical analysis revealed significantly higher APP levels in undifferentiated pluripotent cells (SE and EC) compared with those with well-differentiated subtypes (YST, CC, and TE). C: Expression of APLP2 was not significantly different in various TGCT subtypes. D: Comparison of APP and stem cell signature expression markers in human SE (TCam-2) and EC (NCCIT and NTera-2) cell lines. E: Relative levels of APP were estimated by densitometry and normalization to $\beta$-actin as a loading control. Quantification of APP protein levels revealed a significant overexpression in NTera- 2 cells. Results are from an average of at least four experiments. Data are given as mean (SEM). Differences were calculated using one-way analysis of variance followed by Bonferroni post hoc analysis $(\mathbf{B}$ and $\mathbf{C})$ or unpaired Student's $t$-test $(\mathbf{E}){ }^{*} P<0.05$; ${ }^{* * * * *} P<0.001$. Scale bar $=200 \mu \mathrm{m}$.

These comprehensive alterations in transcription are accompanied by a specific type of differentiation characterized by growth arrest, phenotypic changes, and upregulation of tissue-specific differentiation markers. ${ }^{25}$ To evaluate the functional consequences of HDAC inhibition on cell differentiation, we performed an oligonucleotide microarray analysis. We analyzed gene expression profiles of NTera-2 cells that have been differentiated by VPA, and focused on regulated genes with well-documented functions in maintenance of the pluripotent state and lineage-specific differentiation markers. Gene expression profiling revealed robust down-regulation of stem cell genes or stem cell-associated markers. This set of genes is expressed in the undifferentiated state of embryonic stem cells, early embryogenesis, and malignant EC cells. Furthermore, we determined that expression levels of several differentiation-related transcripts were significantly up-regulated in VPA-differentiated cells including cytokeratin 19 (KRT19) and $\alpha$-fetoprotein (AFP). The most prominent regulated genes ranked by expression level are shown in Figure 2A. To validate that the transcriptional alterations induced by VPA were largely due to HDAC inhibition and to confirm these effects at the level of protein expression, we additionally used two structurally unrelated HDAC inhibitors, the hydroxamate TSA and the cyclic tetrapeptide apicidin. The carboxamide derivative VPM ${ }^{26}$ possesses no HDAC inhibitory activity, and, therefore, served as a negative control (see Supplemental Figures S3 and S4 at http://ajp.amjpathol. org). In accordance with previous studies, treatment with all three HDAC inhibitors significantly decreased cell growth in a dose-dependent manner, whereas even $5 \mathrm{mmol} / \mathrm{L}$ VPM showed no marked reduction in cell viability (Figure 2B). ${ }^{27}$ In contrast to MTS assay results, the $\mathrm{LDH}$ release assay demonstrated no significant acute cytotoxicity with any compounds. LDH leakage measured as an index of cell toxcicity was always less than $10 \%$, as compared with untreated controls (see Supplemental Figure S5 at http://ajp.amjpathol.org). With an order of potency to inhibit HDAC, Western blot analysis revealed a strong reduction in all three core regulators of pluripotency, namely, Sox2, NANOG, and Oct-3/4. Consistent with our hypothesis, VPM demonstrated no effects (Figure $2 \mathrm{C}$ ). These results were confirmed in the NCCIT cell line (see Supplemental Figure S6 at http://ajp. amjpathol.org). To assess the alterations in protein expression of lineage-specific differentiation markers, we focused on the well-established epithelial (ectodermal) marker pan-cytokeratin (pan-CK, clone AE1/AE3, detecting a broad range of keratins including KRT19) and the endodermal marker AFP. As shown in Figure 2D, all three HDAC inhibitors led to a significant increase in both markers and coincided with the extent of hyperacetylated histone $\mathrm{H} 4(\mathrm{H} 4 \mathrm{Ac})$. The total results of microarray and Western blot analyses, and, in particular, the observation that TSA and apicidin exhibited effects indistinguishable from those exerted by VPA clearly indicated that the differentiation process is driven by HDAC inhibition.

\section{HDAC Inhibition Results in Selectively Reduced APP Protein Levels}

Because of the close association between APP and essential stem cell-associated transcription factors in 
A

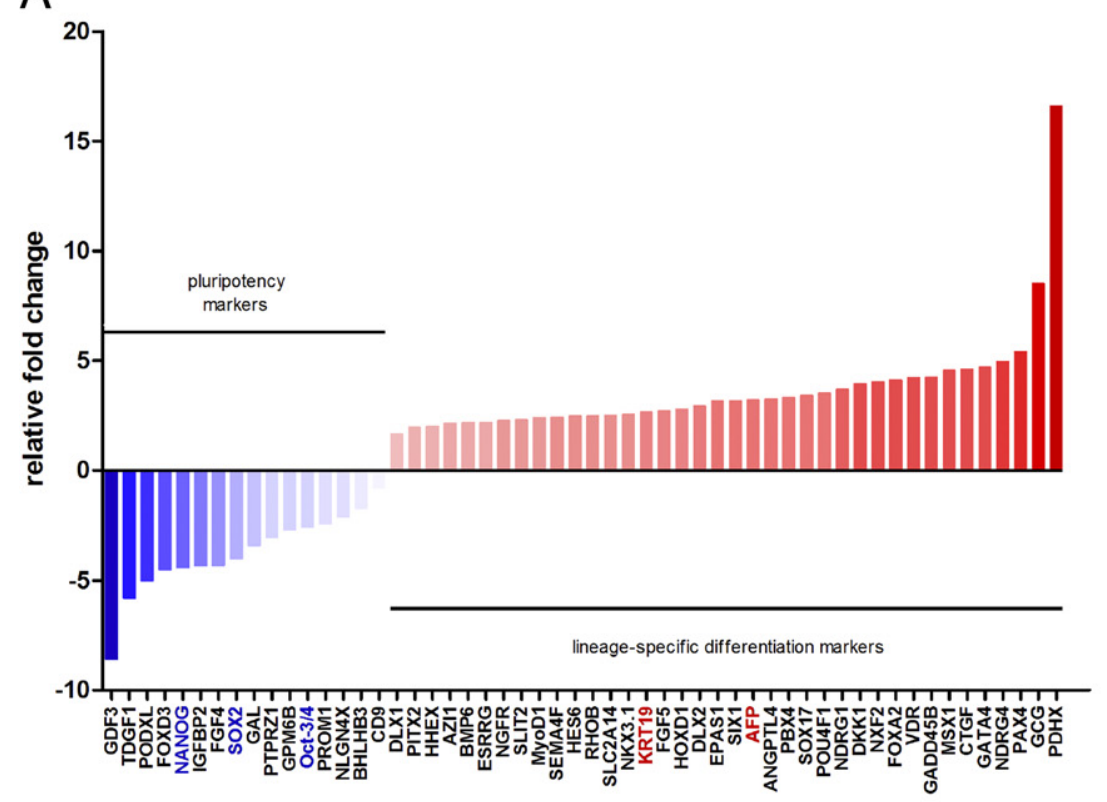

Figure 2. HDAC inhibition modulates gene expression and induces cellular differentiation. A: Functional analysis of genes implicated in differentiation and stem cell self-renewal. Waterfall plot shows differences in expression levels of NTera- 2 cells treated with $5 \mathrm{mmol} / \mathrm{L}$ VPA for 24 hours, compared with untreated controls. Color saturation is proportional to magnitude of the difference from the respective control. Three pluripotency markers (blue) and two lineage-specific differentiation factors (red) were further validated using quantitative PCR and Western blot analysis. B: Three structurally unrelated HDAC inhibitors (VPA, TSA, and apicidin) inhibited tumor proliferation in a dose-dependent fashion in NTera- 2 cells. The carboxamide derivate VPM served as a negative control and demonstrated no growth alteration. Cell proliferation was determined at 48 hours after plating using an MTS survival assay. Each bar represents the mean (SEM) of six experiments (one-way analysis of variance followed by the Bonferroni post hoc test. ${ }^{*} * *$ * $P<$ 0.001 . NTera- 2 cells were incubated with $5 \mathrm{mmol} / \mathrm{L}$ VPM, $5 \mathrm{mmol} / \mathrm{L}$ VPA, $500 \mathrm{nmol} / \mathrm{L}$ TSA, or $1 \mu \mathrm{mol} / \mathrm{L}$ apicidin for 24 hours. Cell lysates were fractionated via SDS-PAGE and immunoblotted for the stem cell genes Sox2, NANOG, and Oct3/4 (POU5F1) (C) or analyzed for ectodermal- (pan-CK) and endodermal-specific (AFP) differentiation markers (D). To assess the extent of histone acetylation, all blots were probed with an antibody against pan-acetylated $\mathrm{H} 4$ (H4Ac). $\beta$-Actin served as a loading control.
B

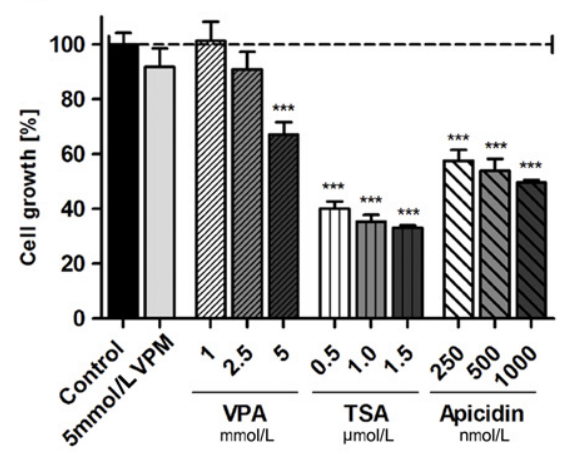

C

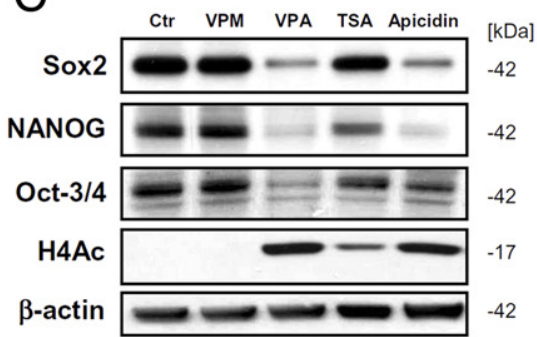

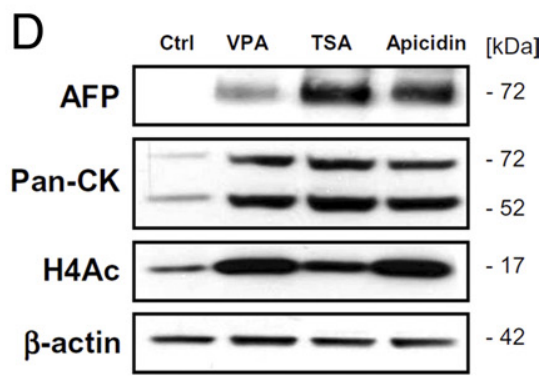

TGCT, we further examined the effects of HDAC inhibition on the protein expression of APP and the homologous family member APLP2. As described previously, each of the two EC cell lines (NTera-2 and NCCIT) were incubated with the aforementioned inhibitors and the negative control VPM, underscoring the involvement of HDAC inhibition. It was observed that treatment with several HDAC inhibitors led to depletion of APP protein levels to an extent similar to that of down-regulation of stem cell transcription factors. However, APLP2 protein expression was entirely unaffected by treatment of HDAC inhibitors, indicating that the underlying mechanism selectively interferes with APP. Exposure with the amidated VPA analogue VPM did not affect H4Ac levels and failed to suppress APP protein expression (Figure 3A). These results suggested that the modulation of APP protein is likely mediated by inhibition of HDAC. To produce immediate effects, VPA was used in high concentrations (up to $5 \mathrm{mmol} / \mathrm{L}$ ). To further attribute therapeutic relevance and determine the effects of long-term administration, EC cell lines were incubated with and without $1 \mathrm{mmol} / \mathrm{L}$ VPA (serum concen- tration in patients treated with VPA) for 2 to 7 days. ${ }^{28}$ Clinically relevant doses of VPA greatly suppressed APP protein levels, and steady state was reached after 48 hours. Again, APLP2 protein levels were not altered. In accordance, H4Ac levels were stably increased at the indicated time points. To exclude the possibility that prolonged VPA treatment also activated apoptosis, we further evaluated the activation of caspase-3. No alterations were observed in full-length caspase-3 (caspase-3 precursor protein) levels, indicating that the substrate was not cleaved, and hence caspase-3 activity was not altered (Figure 3B). To verify the results obtained using Western blot analysis, we further performed immunofluorescence analysis using the polyclonal APP antibody 23850. NTera-2 cells were treated with either $5 \mathrm{mmol} / \mathrm{L}$ VPA or $500 \mathrm{nmol} / \mathrm{L}$ apicidin or were left untreated (control). Morphologic alterations such as cytoplasmic extensions and irregularly shaped nucleoli induced by VPA were consistent with a marked decrease in APP staining and were nearly indistinguishable from those evoked by apicidin (Figure 3C). 
A

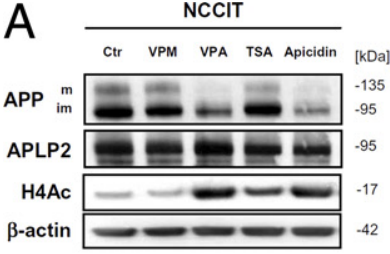

B

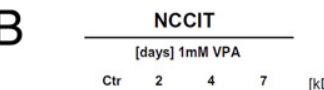

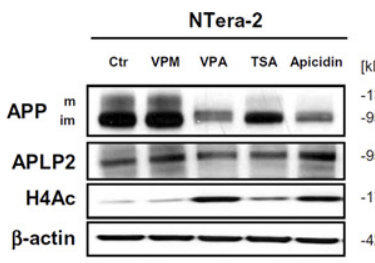

Ntera-2

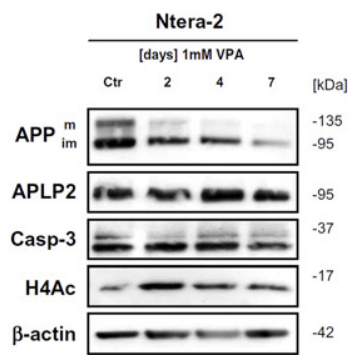

C [kDa] $-135$
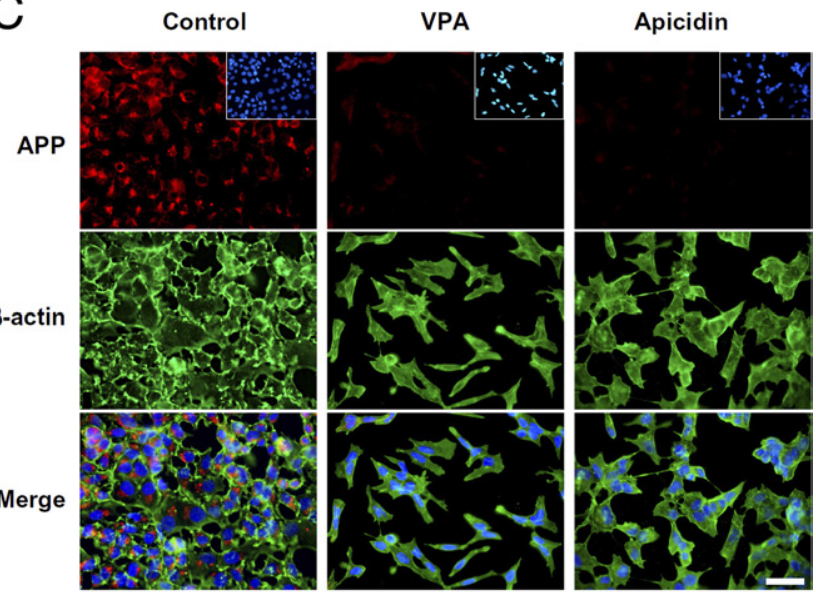

Figure 3. APP protein levels are specifically reduced after HDAC inhibitor treatment. A: Cell extracts from NCCIT and NTera-2 cells were obtained after treatment with $5 \mathrm{mmol} / \mathrm{L}$ VPM, $5 \mathrm{mmol} / \mathrm{L}$ VPA, $500 \mathrm{nmol} / \mathrm{L}$ TSA, $1 \mu \mathrm{mol} / \mathrm{L}$ apicidin, or untreated controls (Ctr) for 24 hours. Cell lysates were analyzed for APP (im, immature; $\mathrm{m}$, mature), APLP2, and H4Ac. $\beta$-Actin was used as a loading control. In addition to VPA, both structurally unrelated HDAC inhibitors TSA and apicidin selectively reduced levels of APP without affecting APLP2 levels. In contrast, equimolar concentration of VPM produced no effects. B: To determine whether physiologic levels of VPA affected full-length APP, both cell lines were incubated with $1 \mathrm{mmol} / \mathrm{L}$ VPA or medium for 2 to 7 days. Medium was replaced every 24 hours, and contained fresh VPA after the initial treatment. APP, APLP2, caspase-3, H4Ac, and $\beta$-actin protein levels were estimated using Western blot analysis. Although APP protein levels were decreased, no changes were observed in APLP2 or full-length caspase-3 levels in both cell lines treated with VPA for up to 7 days. C: NTera-2 cells treated for 24 hours with either $5 \mathrm{mmol} / \mathrm{L}$ VPA, $500 \mu \mathrm{mol} / \mathrm{L}$ apicidin, or medium (control) were evaluated via standard immunofluorescence using specific antibodies against APP (23850, red signals) and $\beta$-actin (green signals). DAPI was used to stain nuclei (insets). Treatment with HDAC inhibitors led to a reduction in cell number differentiated cell architecture, with multiple branched processes extending from the cell body, and was accompanied with loss of APP signals

\section{HDAC Inhibitor-Mediated Suppression of APP Occurs Through a Post-Translational Mechanism}

Next we sought to delineate the molecular mechanism by which HDAC inhibitors down-regulate APP protein levels. Despite the large number of genes differentially regulated by VPA, microarray analysis revealed that APP gene expression was not significantly altered. The absence of decreased APP transcription indicated that post-transcriptional regulatory mechanisms have a predominant role in suppression of APP protein levels. Based on the results of our previous study, we further examined the involvement of the molecular chaperone GRP78. ${ }^{12}$ GRP78, an ER-resident heat shock protein, had previously been identified as a specific APP interaction partner, modulating intracellular maturation and secretion of APP. ${ }^{29-32}$ However, microarray analysis failed to detect an appreciable up-regulation of GRP78 gene expression. Therefore, both EC cell lines were treated with $5 \mathrm{mmol} / \mathrm{L}$ VPA and isolated total RNA at different times (6 to 24 hours), and quantitative PCR was performed. The analysis showed transient up-regulation of GRP78 mRNA. As soon as 6 hours after onset of VPA exposure, we began to observe a significant induction of GRP78 gene expression, which peaked at 12 hours after treatment, followed by a sharp decrease at 24 hours. Moreover, we simultaneously quantified APP mRNA levels and excluded the possibility of differential transcriptional regulation (Figure 4A). To confirm these findings at the protein level, Western blot analysis was performed, which demonstrated that in both cell lines APP inversely correlated with levels of GRP78 during VPA treatment. Whereas APP protein levels decreased, GRP78 protein levels increased in a concentration- dependent manner. The discrepancy between GRP78 mRNA and protein levels can be explained in part by the long protein half-life. ${ }^{33}$ We also analyzed protein expression of heat shock protein 70 (HSP70), a close family member of GRP78. Under the same conditions, HSP70 levels were unchanged, which suggested that VPA is able to specifically up-regulate GRP78 (Figure 4B). In addition, we determined via pharmacologic manipulation of HDAC activity using either TSA and apicidin or VPM that the HDAC inhibitory properties of VPA are responsible for inducing GRP78 expression (Figure 4C). It was suggested that lower protein levels of APP result due to prolonged binding by GRP78 in the ER and thereby enhance its proteasomal degradation. To test this hypothesis, we first determined the time course of APP down-regulation using $5 \mathrm{mmol} / \mathrm{L}$ VPA, and analyzed NTera-2 cells at various times. Western blot analysis revealed that APP protein levels were already diminished after 6 hours, with a further decline through 8 to 10 hours of VPA treatment (Figure 5A). Further experiments were performed with an incubation time of 8 hours using $5 \mathrm{mmol} / \mathrm{L}$ VPA. The wellcharacterized proteasome inhibitor ALLN was used to underline the possibility of proteasome involvement in HDAC inhibitor-mediated APP degradation. APP protein levels were not altered by $50 \mu \mathrm{mol} / \mathrm{L}$ ALLN. However, pretreatment with ALLN for 2 hours completely inhibited degradation of APP in the presence of VPA (Figure 5B).

\section{Differential Expression of GRP78 in TGCT}

Global gene expression analysis of each histologic TGCT subtype revealed that expression of several stem cellspecific genes such as NANOG and POU5F1 (Oct3/4) are strictly limited to undifferentiated EC components. Consistently, these factors were transcriptionally re- 
A

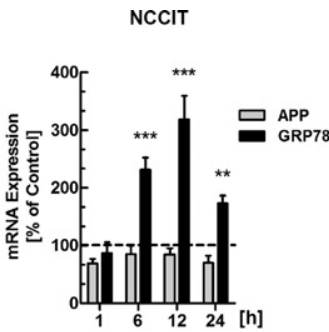

B

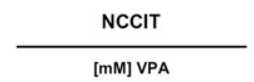

$\begin{array}{llll}1 & 2.5 & 5 & {[\mathrm{kDa}]}\end{array}$

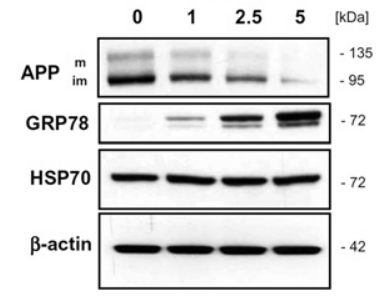

C

NCCIT

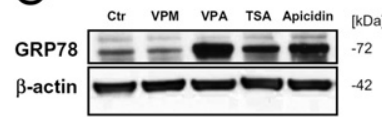

Figure 4. Down-regulation of APP protein levels occurs post-translationally via GRP78. A: Quantitative PCR was used to assess the mRNA levels of APP and GRP78 after treatment with $5 \mathrm{mmol} / \mathrm{L}$ VPA in NCCIT and NTera-2 cell lines. Total RNA was harvested at various times for analysis. Compared with untreated control, only GRP78 mRNA showed a significant increase after 6-hour exposure, whereas APP mRNA levels remained unchanged. Results represent a mean of at least three independent experiments. Data are given as mean (SEM). Differences were calculated using two-way analysis of variance followed by Bonferroni post hoc analyses. ${ }^{*} P<0.05$, ${ }^{* *} P<0.01$, ${ }^{* * * *} P<$ 0.001 . B: Both EC cell lines were exposed for 24 hours to VPA at different concentrations up to $5 \mathrm{mmol} / \mathrm{L}$. Equivalent amounts of protein from each extract were subjected to immunoblotting using antibodies to APP, GRP78, HSP70, and $\beta$-actin. Whereas APP protein levels were down-regulated, VPA increased GRP78 protein levels in a similar concentration-dependent fashion. No changes of the homologous family member HSP70 could be detected with VPA treatment. C: To validate that VPA-induced GRP78 induction is mediated by HDAC inhibition, in addition to $5 \mathrm{mmol} / \mathrm{L} \mathrm{VPA}$, both cell lines were exposed for 24 hours to $500 \mathrm{nmol} / \mathrm{L}$ TSA and $1 \mu \mathrm{mol} / \mathrm{L}$ apicidin. Incubation with $5 \mathrm{mmol} / \mathrm{L} \mathrm{VPM}$ and medium alone (Ctr) served as negative controls. Western blot analysis for GRP78 demonstrated increased levels in response to HDAC inhibitors, corresponding to their HDAC inhibitory property. $\beta$-Actin expression levels served as an internal control.

pressed in differentiated phenotypes (YST, CC, and TE). ${ }^{34,35}$ Furthermore, these studies showed that levels of gene expression of APP were constantly expressed in all histologically distinct subsets. This suggests that posttranslational regulatory mechanisms are responsible for suppressed APP protein levels in differentiated TGCT cell types. To evaluate the involvement of GRP78 during spontaneous differentiation, we analyzed its expression in our panel of patients with TGCT. Poorly differentiated SE and EC subtypes demonstrated weak diffuse cytoplasmic staining, whereas the amount of GRP78 protein was significantly elevated in extra-embryonic differentiated (YST and CC) and somatic differentiated (TE) lineages (Figure 6 A). Expression of GRP78 was predominantly localized in epithelium, with much lower expression in the surrounding stromal cells. Semiquantitative scoring in immunostained sections showed significant dissimilarities between undifferentiated and differentiated samples (Figure $6 \mathrm{~B})$. Because our results are correlative, it is assumed that the induction of GRP78 either by HDAC inhibition or during the gradual transition from an undifferentiated to a differentiated phenotype results in a specific depletion of APP protein levels.

\section{Reduced APP Protein Expression and Decreased Tumor Growth after VPA Treatment in Vivo}

Next we studied the in vivo relevance of HDAC inhibition in TGCT using an established NTera-2 tumor xenograft model. Because of the relatively low incidence of adverse effects and the broad therapeutic spectrum, VPA was used in our in vivo study. ${ }^{36}$ Based on the objective of assessing the efficacy of VPA, the treatment group was divided into a prophylactic and a therapeutic treatment arm. In addition, serum VPA concentrations were measured in treated mice, and reached 30 to $300 \mu \mathrm{mol} / \mathrm{L}$. Prophylactic treatment was begun on day 4 after inoculation, and the therapeutic regimen after subcutanous tumors were palpable, approximately 28 days after inoculation. After 75 days, all mice were sacrificed, and tumors were removed, measured, and weighed (Figure 7A). Compared with vehicle-treated controls, mice that received the therapeutic regimen exhibited a mean (SEM) 61\% (28.3\%) reduced tumor volume. Striking antitumor effects could be observed in the prophylactic setting, that is, $87 \%(22.8 \%)$ reduced tumor volume (Figure $7, \mathrm{~B}$ and $\mathrm{C}$ ). To evaluate the effect of VPA treatment on APP protein levels and to verify effective HDAC inhibition, tumors were lysed from all three cohorts, and Western blot analysis was performed. Compared with no treatment (control), both treatment regimens led to strong reduction in APP protein levels. According to our in vitro

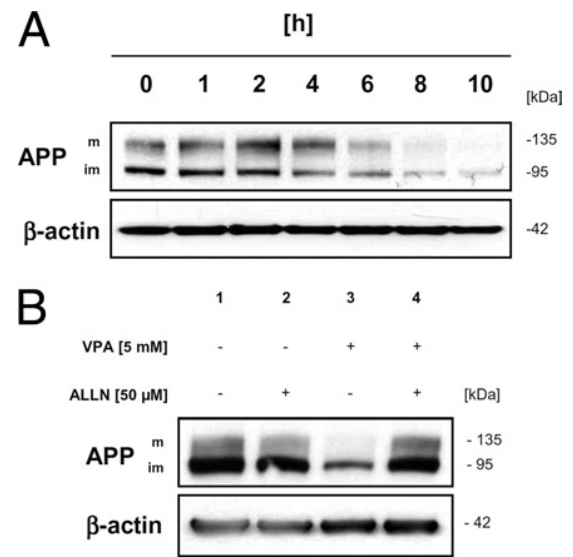

Figure 5. The proteasome inhibitor ALLN blocks APP degradation. A NTera-2 cells were treated with $5 \mathrm{mmol} / \mathrm{L} \mathrm{VPA}$, and proteins were isolated at various times ranging from 1 to 10 hours. APP was increasingly downregulated in a time-dependent manner starting at 6 hours after treatment. B: Effect of ALLN on VPA-induced APP degradation. Equal numbers of NTera-2 cells were either incubated in the presence of either medium alone (lane 1), preincubated for 2 hours in the presence of $50 \mu \mathrm{mol} / \mathrm{L}$ ALLN followed by incubation in medium for 8 hours (lane 2), preincubated for 2 hours with medium and treated with $5 \mathrm{mmol} / \mathrm{L}$ VPA for 8 hours (lane 3 ), or preincubated for 2 hours in the presence of $50 \mu \mathrm{mol} / \mathrm{L}$ ALLN followed by incubation in the presence of $5 \mathrm{mmol} / \mathrm{L}$ VPA for 8 hours (lane 4). The effect of VPA on APP protein levels was largely reversed by pretreatment of cells with the proteasome inhibitor ALLN 
A

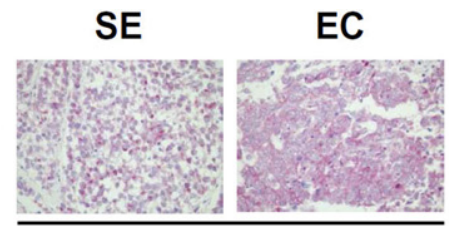

undifferentiated

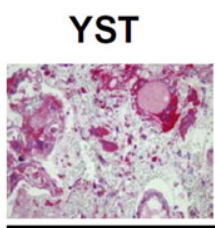
differentiated

Figure 6. Immunohistochemical expression pattern of GRP78 in pluripotent germ cell tumors. A: Representative images demonstrating GRP78 protein expression in undifferentiated and differentiated TGCT subgroups. GRP78 was expressed weakly within the cytoplasms of SE and EC. In contrast, strong staining is visible in differentiated cohorts such as YST, CC, and terminal differentiated TE. B: GRP78-positive cells were quantified by assessing the immunoreactive score. All values are given as mean (SEM). Data were calculated and statistically analyzed using one-way analysis of variance and Bonferroni post hoc tests. ${ }^{* * * *} P<0.001$. Scale bar $=100 \mu \mathrm{m}$ ).

results, no significant changes in APP protein levels were observed between therapeutic and prophylactic VPA, indicating that prolonged treatment stabilizes basal and low APP protein levels. Consistently, accumulated H4Ac was determined in all treated cohorts (Figure 7D).

\section{Histopathologic Features and Differential APP Expression in Xenografts Reflect the Human Phenotype}

To survey the tissue composition of TE, dissected fresh tumor tissues were subsequently paraffin embedded and sectioned. Xenografted NTera-2 demonstrated a unique pleomorphic histologic appearance and exhibited nearly all features of human teratocarcinomas. These tumors contained solid islets of undifferentiated EC cells surrounded by stroma. In addition to numerous highly differentiated epithelial formations in the form of glandular structures and primitive epithelium, mesenchymal formations in the form of cartilage (Figure 8, A and B), and smooth and striated muscles (data not shown) were observed. In contrast to the findings of Andrews et al, ${ }^{17}$ neuronal structures such as neural rosettes or neural tube-like structures could not be detected in our analyzed sections. Immunohistochemical staining using the monoclonal APP antibody 22C11 revealed a clear distinguishable pattern. Undifferentiated pluripotent EC cells demonstrated abundant expression of APP. Consistently, serial sections as well as double-immunolabeling experiments using APP and the proliferation marker Ki-67 revealed a strong correlation in undifferentiated highly proliferating parts of the TE. Terminally differentiated ectodermal, endodermal, and mesodermal lineages corresponding to epithelial, glandular, surrounding stroma, and cartilage structures showed low or no APP and Ki-67 expression (Figure 8, C-J).

\section{Secreted SAPP Partially Reverses HDAC Inhibitor-Induced Differentiation}

APP overexpression potently drives cellular proliferation in isoform and cell types in an independent manner (see
Supplemental Figure S7 at http://ajp.amjpathol.org). Furthermore, we have recently reported that SAPP completely rescued VPA-mediated growth arrest. ${ }^{12}$ In this regard, previous studies have demonstrated that several disease-relevant growth factors were capable of reverting growth arrest in EC cells but were unable to block differentiation induced by various differentiating agents. ${ }^{37,38}$ Therefore, we wondered whether the differentiation induction exerted by HDAC inhibition could be modulated by exogenous addition of $\operatorname{SAPP} \alpha$. Thus, we used human recombinant SAPP and conditioned media from APP-overexpressing cells (SH-SY5Y APP695 ${ }_{\text {wt }}$ ) or mock-transfected negative controls and co-treated NTera-2 cells with increasing concentrations of apicidin. Human recombinant peptides and SAPP purified from conditioned media of APP-overexpressing cells migrated on SDS-PAGE as a single band at approximately $110 \mathrm{kDa}$. Two APP antibodies were used to detect SAPP processing products. The monoclonal antibody 22C11 recognizes an $\mathrm{N}$-terminal epitope (residues 66 to 81 of human APP) and detects all SAPP species ( $\mathrm{APPP} \alpha$ and SAPP $\beta$ ), and the monoclonal APP/A $\beta$-antibody $W$-02 recognizes a region between amino acids 5 and 8 of the $A \beta$ sequence and selectively detects SAPP $\alpha$ but not SAPP $\beta$. Both antibodies resulted in a similar immunoblot staining pattern (Figure 9A), whereas a specific SAPP $\beta$ antibody that selectively recognizes the C-terminus of human SAPP $\beta$ failed to detect any antigen band (data not shown). Application of both SAPP $\alpha$ and apicidin completely abolished pan-CK induction and partially abolished induction of AFP. This rescue effect could not be obtained by using media alone or conditioned media from mock-treated cells. To rule out that SAPP $\alpha$ directly reduces the potency to inhibit HDAC, we could show no substantial changes in APP and H4Ac levels between both conditions (Figure 9, B and C). These findings indicated that APP $\alpha$ either activates protective cascades that interfere with differentiation pathways or may counteract directly with HDAC inhibitorinduced signal pathways. Based on these results, we sought to determine whether APP down-regulation by APP-specific siRNA modulates the expression of lineagespecific differentiation markers. Both siRNA duplexes 

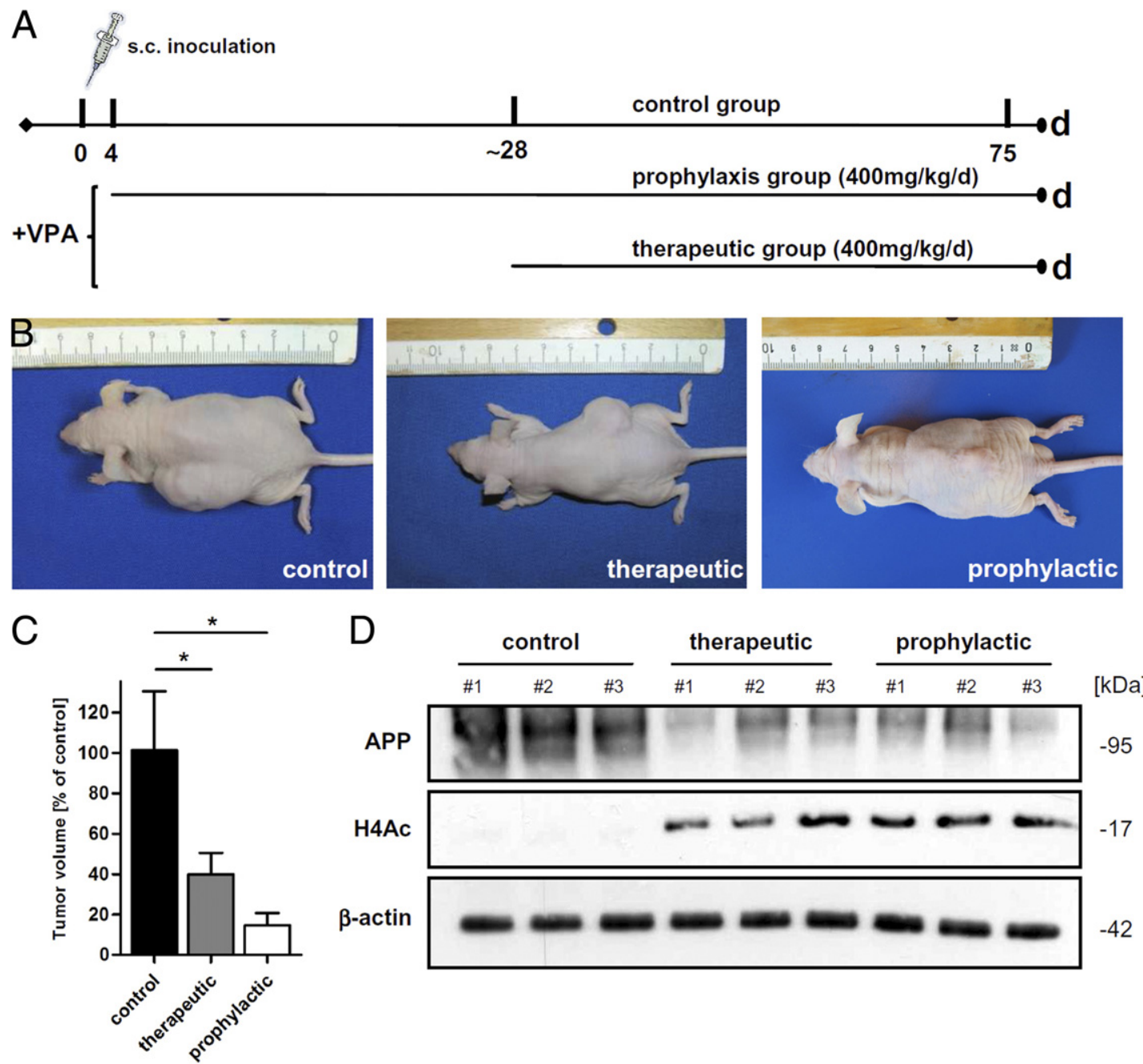

Figure 7. VPA treatment inhibits tumor growth and reduces APP protein levels in vivo. A: Six-week-old mice with established NTera-2 xenografts were treated with $400 \mathrm{mg} / \mathrm{kg} / \mathrm{d}$ VPA at either 4 days after inoculation (prophylactic group) or at an advanced stage after 28 days (therapeutic group). Mice in the vehicle group (controls) received only regular drinking water. Recipient nude mice were sacrificed at 75 days after injection. B: Images of representative NTera- 2 mice with xenograft tumors. C: Histogram representing the average tumor volume estimated in control, therapeutic, and prophylactic groups after sacrifice $(n=15$ in each group). One-way analysis of variance revealed a significant difference in tumor volume among the groups $(P<0.005)$. Unpaired $t$-test analysis showed a significant difference in tumor volume between the control and prophylactic groups $(P=0.01)$. VPA treatment of tumors of advanced stage also significantly reduced tumor growth $(P<0.05)$. D: Effect on APP protein and H4Ac levels was determined using Western blot analysis. $\beta$-Actin served as a loading control for total protein extracts. Data are given as mean (SEM). Differences were calculated using one-way analysis of variance followed by unpaired $t$-test analyses. * $P<0.05$.

(APP siRNA\#1, s1500; and APP siRNA\#2, s1501) efficiently suppressed APP protein expression, whereas vehicle treatment or transfection with random siRNA demonstrated no alterations. Evaluation of lineage-specific genes revealed a significant increase in AFP and pan-CK in APP siRNA-transfected cells (Figure 10).

\section{Discussion}

There is no doubt that APP and its proteolytically derived $A \beta$ species contribute significantly to the pathogenesis of Alzheimer's disease. ${ }^{5}$ Despite progress made in the last two decades, the normal physiologic role or roles of this ubiquitously expressed protein have remained largely unknown. The perhaps best-studied functions of APP and its $\alpha$ cleavage product SAPP $\alpha$ are the growth-promoting, trophic, and migratory activity in vitro and in vivo ${ }^{9}$. Previous studies have revealed that genetic overexpression, pharmacologic augmentation, and addition of recombinant proteins of APP essentially promoted cancer growth. ${ }^{10,12,39-41}$ Consistently, siRNA-mediated depletion of APP expression effectively diminished growth of several aggressive cancer types in vitro. ${ }^{11,42,43}$ Complementary in vivo evidence of the causal involvement of APP in tumor growth was examined by Takayama et al, ${ }^{44}$ who showed that siRNA-mediated knockdown of APP significantly reduced tumor growth rate, even in tumors of advanced stage. In this context, we and other groups have presented evidence that APP is up-regulated and essentially contributes to tumorigenesis in various hematologic and solid malignant lesions including oral squamous cell carcinoma, ${ }^{42}$ melanoma, ${ }^{43}$ acute myeloid leukemia, ${ }^{45}$ Epstein-Barr virus-negative Burkitt's lymphoma, ${ }^{46}$ and cancers of the pancreas, ${ }^{11,12}$ colon, ${ }^{12}$ thyroid gland, ${ }^{47}$ parathyroid glands, ${ }^{48}$ and nasopharynx. ${ }^{49}$ Furthermore, evidence from clinical and epidemiologic studies has 

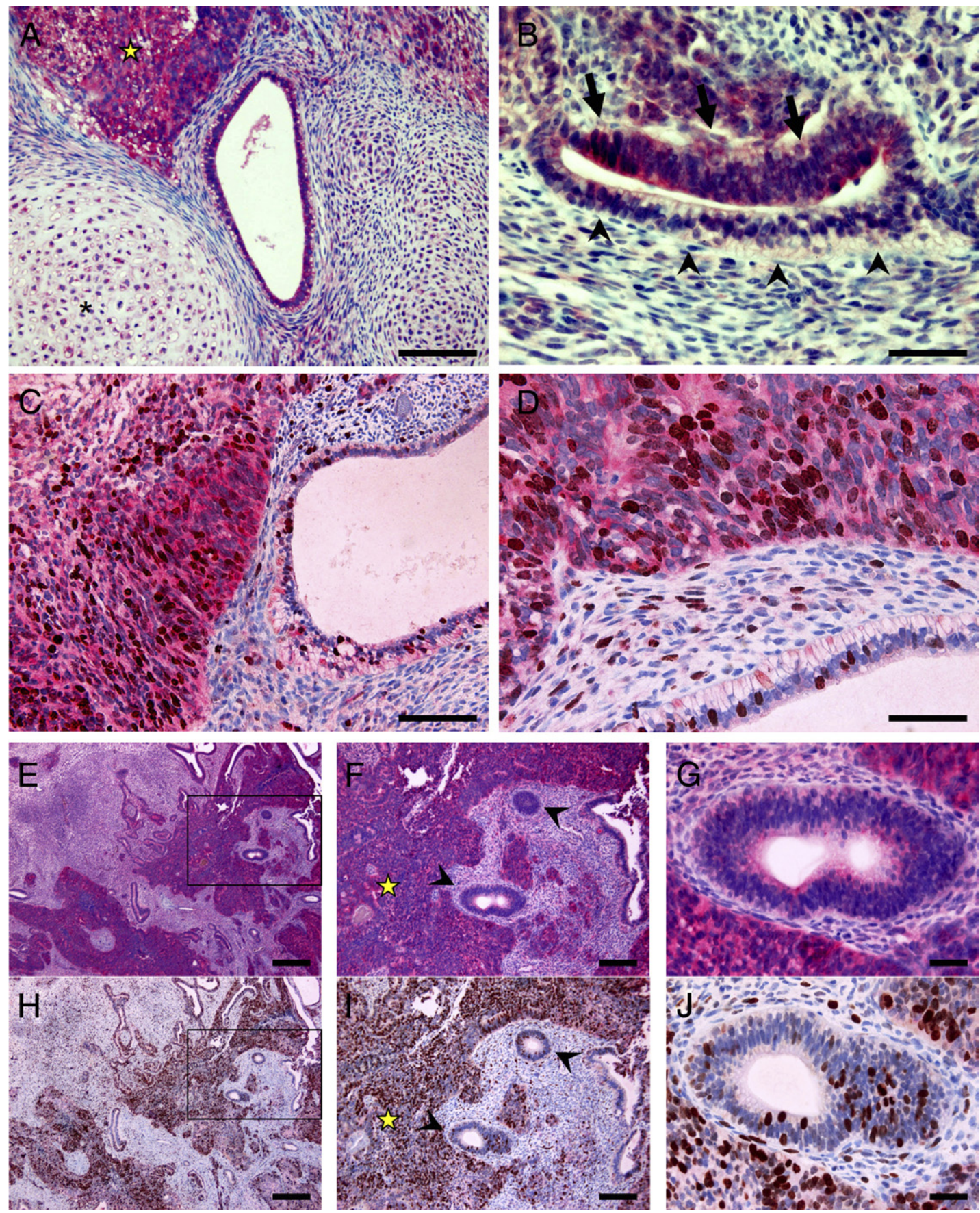

Figure 8. APP staining and composition of NTera-2 xenograft tissue reflects differentiation pattern of human TGCT. A: Undifferentiated tumor tissue (star) showed abundant APP protein expression. Note the low or undetectable APP staining in differentiated cartilage (asterisk), epithelial tissue, and surrounding stroma. B: In detail, low-differentiated epithelial cells (arrows) demonstrated pronounced staining for APP when compared with terminal differentiated epithelial tissue (arrowheads) and enclosed stromal elements. C and D: Double-staining of APP and the proliferation marker Ki-67 revealed a co-localization only in the undifferentiated and proliferating compartments. Terminal differentiated tissues were negative for both markers. Immunohistochemical analysis of serial sections with APP (E-G) and Ki-67 (H-J) antibodies in NTera-2 xenografts. Undifferentiated tumor tissue (stars) demonstrated strong APP (red) and Ki-67 (brown) signals. $\mathbf{F}$ and $\mathbf{I}$ are magnified images of the boxed portions of $\mathbf{E}$ and $\mathbf{H}$. G and $\mathbf{J}$ are further magnified images of portions of $\mathbf{F}$ and $\mathbf{I}$ marked with arrowheads (lower) In contrast, terminal differentiated epithelium (arrowheads) and surrounding stroma (mesenchymal cells) demonstrated only low levels of both antigens. Scale bars: $500 \mu \mathrm{m}(\mathbf{E}$ and $\mathbf{H}) ; 200 \mu \mathrm{m}(\mathbf{A}, \mathbf{F}$, and $\mathbf{I}) ; 100 \mu \mathrm{m}(\mathbf{C}) ; 50 \mu \mathrm{m}(\mathbf{B}, \mathbf{D}, \mathbf{G}, \mathbf{J})$

shown a strong association between APP expression and poor prognosis in several cancer types. ${ }^{42,44}$

The objective of the present study was to examine the effect of APP in human TGCT by analyzing human TGCTderived cell lines, tissue samples, and an established tumor xenograft mouse model. Furthermore, the pharma- comodulation of APP via HDAC inhibitors in vitro and in vivo was investigated, and the biological plausibility and relevance of potential molecular mechanisms was evaluated. Herein we report for the first time that APP is exclusively expressed in pluripotent and poorly differentiated germ cell cancer. These cells, in particular human 
A

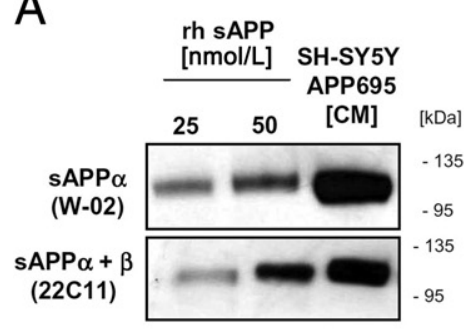

B

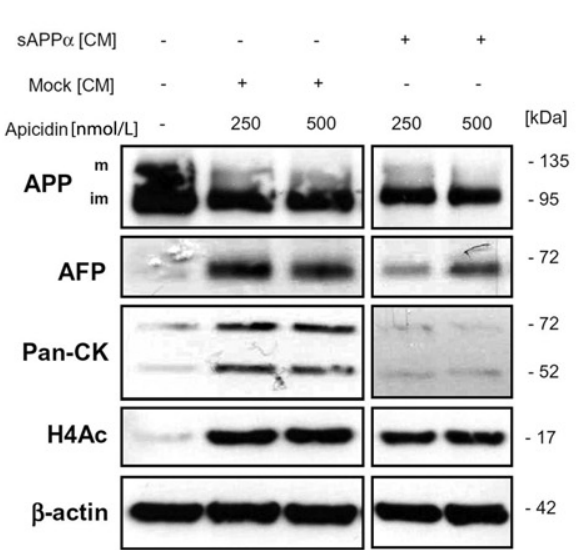

C

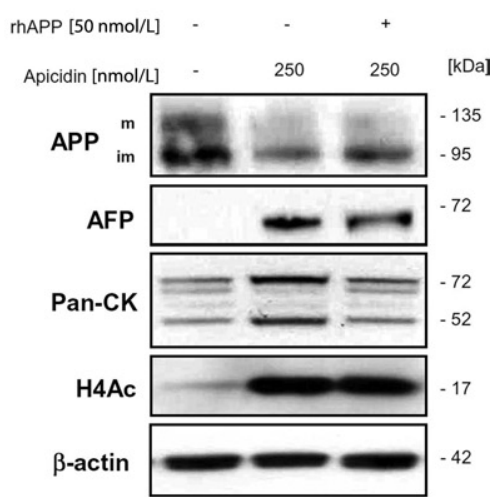

Figure 9. Exogenous addition of secreted APP partially rescues HDAC inhibitor-induced differentiation. A: Western blot analysis of 25 and 50 nmol/L purified recombinant human SAPP and supernatant of transfected SH-SY5Y cells stably overexpressing APP695 ${ }_{\mathrm{wt}}$. The APP/A $\beta$-specific antibody W-02 selectively detects $\operatorname{sAPP} \alpha$, whereas the N-terminal APP antibody 22C11 detects all secreted APP species ( $\mathrm{SAPP} \alpha$ and sAPP $\beta$ ). B: NTera- 2 cells were incubated with increasing concentrations of apicidin ( 250 and $500 \mathrm{nmol} / \mathrm{L}$ ) and either co-treated with conditioned media (CM) from SH-SY5Y APP695 $5_{\mathrm{wt}}-\mathrm{Overexpressing} \mathrm{cells} \mathrm{(sAPP} \alpha$ ) or mock-transfected negative controls for 24 hours. As additional control, cells were incubated with medium alone. C: NTera- 2 cells were exposed to 250 nmol/L apicidin alone or together with $50 \mathrm{nmol} / \mathrm{L}$ human recombinant sAPP for 24 hours. Cells cultured in medium alone served as a negative control. Western blot analysis using pan-CK-specific (ectodermal marker) and AFP-specific (endodermal marker) antibodies demonstrated that parallel addition of sAPP $\alpha$ prevented apicidin-mediated induction of differentiation genes. The possibility that the HDAC inhibiting activity was altered by conditioned media was excluded by analyzing levels of APP and H4Ac. The levels of $\beta$-actin served as loading control.

EC cells, have a transcription profile similar to human embryonic stem cells. The potential of both to differentiate into a wide range of tissues is well attested; however, little is known of the complex regulatory factors and mechanisms that control this process. ${ }^{3,50}$ In our series of primary TGCT, APP expression disappeared together with well-established key pluripotency genes such as Sox1, NANOG, and POU5F1 (Oct3/4) through differentiation to YST, CC, and TE cells. In contrast, the closest homologue family member, APLP2, was continuously expressed in all histologic TGCT subtypes.

Several studies have provided evidence that induction of EC differentiation is accompanied by loss of tumorige-

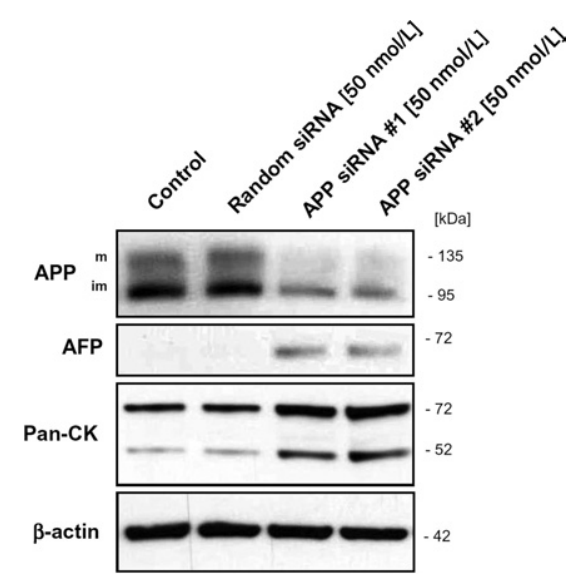

Figure 10. siRNA-mediated knockdown of APP up-regulates lineage-specific differentiation markers. NTera- 2 cells were transiently transfected with the indicated siRNA pools (APPsiRNA \#1, s1500; and APPsiRNA \#2, s1501) that selectively targets APP. Cells treated with the vehicle (Lipofectamine 2000; control) or transfected with $50 \mathrm{nmol} / \mathrm{L}$ non-targeting control siRNA (random siRNA) were used as controls. Cells were maintained for 96 hours under serum-free conditions, lysed, and analyzed using indicated antibodies. Western blot analysis confirmed that both siRNA duplexes effectively downregulated APP protein expression. Vehicle-treated cells or equimolar amounts of random siRNA demonstrated no effect. In contrast to controls, APP knockdown resulted in up-regulation of AFP and pan-CK. nicity, pluripotency, and transcriptional repression of various growth-promoting factors (eg, transforming growth factor- $\alpha$, teratocarcinoma-derived growth factor 1 , and fibroblast growth factor 4). Exogenous additions of all of these factors were able to rescue growth inhibition but could not prevent terminal differentiation exerted by various differentiation-inducing agents (eg, retinoic acid or hexamethylene bisacetamide). ${ }^{37,38}$ In a previous study, we demonstrated that parallel addition of SAPP, primarily containing $\operatorname{SAPP} \alpha$, completely rescued HDAC inhibitorinduced growth arrest. ${ }^{12}$ In this study, using the more potent HDAC inhibitor apicidin, we provided evidence that SAPP $\alpha$ partially reversed induction of lineage-specific differentiation markers such as the ectodermal marker pan-CK and the endodermal marker AFP. It is suggested that multiple signal transduction cascades, initiated by $\operatorname{SAPP} \alpha$, counteract with differentiation-induced pathways. Although a possible role in modulating apoptosis signaling cascades has been frequently reported, more studies to elucidate the molecular pathways downstream are required to fully understand the biological properties and potency of $\operatorname{SAPP} \alpha{ }^{51,52}$ The critical role of APP in TGCT was further underlined by the observation that selective reduction of APP expression via siRNA silencing induced the expression of lineage-specific differentiation markers. The results coincided with the findings from a recent study that revealed that siRNAmediated knockdown of APP in metastatic melanoma cells increased protein levels of differentiation-specific markers and caused irreversible commitment to terminal differentiation. ${ }^{43}$ Furthermore, there is compelling evidence that APP is also highly expressed and processed in the human embryonic stem cell line H9/WA09, compared with lineage-committed neuroblastoma cells. ${ }^{53}$ Together with our results, these corroborative findings underline that APP has a crucial role in maintaining a pluripotent undifferentiated state of transformed pluripo- 
tent germ cells and that it is conceivable that it also participates to preserve developmental potential during the stem cell stage.

Profiling studies using the oligonucleotide microarray approach have attempted to elucidate histologic subtype-specific gene expression patterns in various patient samples of TGCT and cell lines, and have frequently identified long lists of differentially expressed genes. In contrast to the predominant expression of the stem cell signature in undifferentiated ES and SE, mRNA levels of APP were widely expressed in a variety of TGCT subtypes including CC, YST, and TE. ${ }^{34,35}$ To bring these results in line with our study, we proposed the involvement of a post-translational regulatory mechanism leading to suppressed APP protein levels in differentiated TGCT subgroups. In this context, a similar discrepancy between APP mRNA and protein levels could be observed by treating EC cell lines with HDAC inhibitors.

Extensive evidence in vitro and in vivo demonstrates that HDAC inhibitors potently induce cell differentiation, growth inhibition, cell cycle arrest, and programmed cell death. ${ }^{25,54}$ The exerted pleiotropic effects of these epigenetic compounds predominantly occur through transcriptional modulation of specific preprogrammed genes. ${ }^{55}$ However, analysis of transcriptomic changes does not necessarily reflect the potency of induced biological effects, in particular because of neglecting the influence of post-translational mechanisms by which HDAC inhibitors alter the expression and function of cancer-associated proteins. In the present study, we used three structural unrelated HDAC inhibitors (VPA, TSA, and apicidin) and clearly demonstrated that HDAC inhibition selectively decreased APP protein levels that were accompanied by marked down-regulation of the stem cell signature (Sox2, NANOG, and Oct-3/4). Despite the robust depletion of APP, we could not detect significant changes in APLP2 levels after HDAC inhibitor treatment. In addition, we confirmed the association with HDAC inhibition by using the carboxamide VPM as a negative control. In this analogue compound, the free carboxylic group of VPA is amidated, which apparently leads to loss of HDAC inhibitory activity. ${ }^{26}$ The concerted actions of several HDAC inhibitors on APP, in conjugation with suppression of the stem cell signature, was in accordance with the induction of differentiation of transformed EC cells. However, in addition to these apparent similarities, stem cell genes were transcriptionally regulated, whereas suppressed APP protein levels by HDAC inhibitors are not due to changes in the level of APP transcript, as shown using the oligonucleotide microarray approach and RT-PCR. To further delineate the predominant involvement of a post-translational mechanism leading to decreased APP protein levels, we analyzed the ER heatshock protein GRP78. Under normal conditions, this constitutively expressed molecular chaperone is involved in many cellular processes including correct folding and assembly of newly synthesized proteins that are transported through the secretory pathway. ${ }^{56}$ In contrast, induction or overexpression of GRP78 causes prolonged binding, hinders correct maturation, and facilitates proteasomal degradation of target proteins. This sophisti- cated process is termed "ER-associated protein degradation," and relative to GRP78, has been previously described for a selective subset of proteins. ${ }^{57,58}$ GRP78 was observed to associate intracellularly with the immature unfolded form of APP. This interaction causes retention in the early secretory compartments and consecutively impairs maturation and secretion of APP. ${ }^{29-31}$ Moreover, GRP78 binds with a high and specific affinity to APP without affecting the other APP family members APLP1 and APLP2. ${ }^{32}$ Supporting our hypotheses, HDAC inhibitor treatment resulted in increased GRP78 mRNA and protein levels. In addition, expression of the homologous family member HSP70 was not affected, which suggests that HDAC inhibition specifically regulates GRP78 induction. Consistent with these results, a recent study revealed an HDAC-specific binding site in the Grp78 promoter (ER stress response element), which probably could explain the selective induction of GRP78. ${ }^{59}$ We hypothesize that HDAC inhibitor-mediated up-regulation of GRP78 causes prolonged binding of APP in the ER and subsequently leads to its proteasomedependent degradation on the cytosolic side of the ER membrane. The involvement of the ubiquitin-proteasome pathway in APP degradation was further supported by the finding that the proteasome inhibitor ALLN nearly abolished VPA-induced degradation of APP. Although MG-132, another peptide aldehyde and proteasome inhibitor, was found to be more potent and specific than ALLN, previous studies have demonstrated the limited use of MG-132 because of multiple effects on maturation and processing of APP. ${ }^{60}$ Although other GRP78 ligands have been identified as ER-associated protein degradation substrates, ${ }^{57,58}$ and APP seems to be degraded by the ubiquitin-proteasome system, it is still possible that cytosolic calpains and lysosomal proteases, which are also blocked by ALLN, are involved in this process.

We next attempted to translate our in vitro observations into in vivo relevance. Therefore, we evaluated the histopathologic expression profile of GRP78 in TGCT tissue samples. Consistent with our in vitro results, strongly increased levels of GRP78 protein were found in well-differentiated TGCT subtypes, in particular in mature TE, whereas in undifferentiated SE and EC, only barely detectable expression was observed. This result extends previous reports that consistently demonstrated the fundamental role of GRP78 in physiologic cell differentiation. ${ }^{61-65}$ We presume that GRP78 induction could be a key event for triggering down-regulation of APP in differentiated TGCT tissues. Furthermore, the inverse correlation between APP and GRP78 that occurs during spontaneous TGCT differentiation in vivo is exactly reflected in the molecular mechanism by which HDAC inhibitors induce EC cell differentiation, leading to decreased APP protein levels in a post-translational manner.

Another main objective of the present study was to demonstrate the in vivo efficacy of a HDAC inhibitor in a established NTera-2 xenograft mouse model. The compounds used in this study belong to several structural classes. Potent HDAC inhibitors such as the pan-HDAC inhibitor TSA (hydroxamic acid) or the partially irreversible HDAC inhibitor apicidin (cyclic tetrapeptide) are of 
limited therapeutic use and can be studied only in preclinical settings. ${ }^{27,66}$ Therefore, we used the short fatty acid VPA because it is a well-tolerated orally bioavailable anti-epileptic agent and causes only mild adverse effects in animal experiments and in clinical trials. ${ }^{36,54} \mathrm{We}$ treated NTera-2 xenografts in two treatment modes: prophylactic and therapeutic treatment arms. Both treatment regimens resulted in significantly decreased tumor growth at therapeutic doses of VPA. These data are in accordance with recent studies that showed that longterm administration of VPA severely affects tumor volume in prostate gland ${ }^{67}$ and renal ${ }^{68}$ cancer xenografts, prevents tumor formation, and significantly improves survival in Ptch-deficient mice, respectively. ${ }^{69} \mathrm{~A}$ novel finding in our approach is that both treatment methods remarkably decreased APP protein levels, which were accompanied by up-regulated H4Ac levels. These effects were supported by our in vitro work, which showed that prolonged treatment with physiologic VPA concentrations resulted in down-regulation of APP to steady state. It is likely that the above-mentioned effects are not specific to VPA but are an effect that can be mimicked by other HDAC inhibitors currently undergoing clinical trials. Despite the difficulty in comparing the plethora of mechanisms of growth arrest triggered by HDAC inhibitors, we conclude that effectively suppressed levels of the tumor mitogen APP contribute in part to the observed growth inhibitory effects in vivo.

In addition to these important tumor biological aspects, NTera-2 xenografts are an exceptional tool for examination of cellular differentiation in vivo. Similar to human embryonic stem cells, implanted NTera-2 cells form complex TE composed of all three germ cell layers. ${ }^{17,50} \mathrm{~A}$ major difference between these two is that human embryonic stem cells form benign TE, completely lacking undifferentiated cells, whereas grafted EC are characterized by persistence of undifferentiated cell populations, histopathologically resembling human teratocarcinomas. ${ }^{18}$ APP expression was limited to solid areas of undifferentiated cells, whereas mature and terminally differentiated tissues (eg, glands, epithelial cells, and cartilage) demonstrated dramatically reduced levels. This specific phenotype mirrored exactly our results in patient samples of TGCT.

In conclusion, the presence of APP protein together with the similar expression patterns of stem cell markers in undifferentiated human TGCT subtypes and its downregulation during spontaneous differentiation indicate that APP is as a reliable biomarker for transformed human pluripotent stem cells. It is noteworthy that the percentages of EC stem cells in primary stage I nonseminomatous TGCT are pathologic predictors of occult metastasis, correlate with a higher risk of relapse, and dictate treatment. ${ }^{70,71}$ In this regard, APP immunohistochemistry could be applied as a useful tool for detection of EC cells. We also investigated connections and similarities between HDAC inhibitor-mediated and spontaneous EC differentiation, and identified GRP78 as a key factor that triggers down-regulation of APP. We have provided evidence that oral administration of the HDAC inhibitor VPA suppressed tumor growth and depleted endogenous
APP protein levels in vivo. These promising results shed light on the significance of APP as a novel molecular target and broaden the therapeutic potential of HDAC inhibitors in the clinical treatment of TGCT.

\section{Acknowledgments}

We thank Hubert Schorle (University of Bonn) for providing the TCam-2 cell line, Edward H. Koo (University of California, San Diego) for the CHO APP751 $1_{w t}$ cell line, Gerd Multhaup (University of Berlin) for the 23850 antiserum, Katwijik Chemie BV for valpromide, and Heike Siebert (University Medicine Goettingen) for ALLN. We also thank Anke Klages, Rolf Kleinhans, and Marion Striepe for technical assistance.

\section{References}

1. McGlynn KA, Devesa SS, Sigurdson AJ, Brown LM, Tsao L, Tarone RE: Trends in the incidence of testicular germ cell tumors in the United States. Cancer 2003, 97:63-70

2. Horwich A, Shipley J, Huddart R: Testicular germ-cell cancer. Lancet 2006, 367:754-765

3. Andrews PW: From teratocarcinomas to embryonic stem cells. Philos Trans R Soc Lond B Biol Sci 2002, 357:405-417

4. Ben-Porath I, Thomson MW, Carey VJ, Ge R, Bell GW, Regev A Weinberg RA: An embryonic stem cell-like gene expression signature in poorly differentiated aggressive human tumors. Nat Genet 2008, 40:499-507

5. Selkoe DJ: Alzheimer's disease: genes, proteins, and therapy. Physiol Rev 2001, 81:741-766

6. Rossjohn J, Cappai R, Feil SC, Henry A, McKinstry WJ, Galatis D, Hesse L, Multhaup G, Beyreuther K, Masters CL, Parker MW: Crystal structure of the $\mathrm{N}$-terminal, growth factor-like domain of Alzheimer amyloid precursor protein. Nat Struct Biol 1999, 6:327-331

7. Sisodia SS: Beta-amyloid precursor protein cleavage by a membrane-bound protease. Proc Natl Acad Sci USA 1992, 89:6075-6079

8. Bayer TA, Cappai R, Masters CL, Beyreuther K, Multhaup G: It al sticks together: the APP-related family of proteins and Alzheimer's disease. Mol Psychiatry 1999, 4:524-528

9. Zheng $\mathrm{H}$, Koo EH: Biology and pathophysiology of the amyloid precursor protein. Mol Neurodegener 2011, 6:27

10. Saitoh T, Sundsmo M, Roch JM, Kimura N, Cole G, Schubert D, Oltersdorf T, Schenk DB: Secreted form of amyloid beta protein precursor is involved in the growth regulation of fibroblasts. Cell 1989 , 58:615-622

11. Hansel DE, Rahman A, Wehner S, Herzog V, Yeo CJ, Maitra A: Increased expression and processing of the Alzheimer amyloid precursor protein in pancreatic cancer may influence cellular proliferation. Cancer Res 2003, 63:7032-7037

12. Venkataramani V, Rossner C, Iffland L, Schweyer S, Tamboli IY, Walter J, Wirths O, Bayer TA: Histone deacetylase inhibitor valproic acid inhibits cancer cell proliferation via down-regulation of the Alzheimer amyloid precursor protein. J Biol Chem 2010, 285:1067810689

13. Tomita S, Kirino Y, Suzuki T: Cleavage of Alzheimer's amyloid precursor protein (APP) by secretases occurs after O-glycosylation of APP in the protein secretory pathway: identification of intracellular compartments in which APP cleavage occurs without using toxic agents that interfere with protein metabolism. J Biol Chem 1998, 273:6277-6284

14. Huttunen HJ, Guenette SY, Peach C, Greco C, Xia W, Kim DY, Barren C, Tanzi RE, Kovacs DM: HtrA2 regulates beta-amyloid precursor protein (APP) metabolism through endoplasmic reticulum-associated degradation. J Biol Chem 2007, 282:28285-28295

15. Kaneko M, Koike H, Saito R, Kitamura Y, Okuma Y, Nomura Y: Loss of HRD1-mediated protein degradation causes amyloid precursor protein accumulation and amyloid-beta generation. J Neurosci 2010 , 30:3924-3932 
16. You JS, Kang JK, Seo DW, Park JH, Park JW, Lee JC, Jeon YJ, Cho EJ, Han JW: Depletion of embryonic stem cell signature by histone deacetylase inhibitor in NCCIT cells: involvement of NANOG suppression. Cancer Res 2009, 69:5716-5725

17. Andrews PW, Damjanov I, Simon D, Banting GS, Carlin C, Dracopol NC, Fogh J: Pluripotent embryonal carcinoma clones derived from the human teratocarcinoma cell line Tera-2. Differentiation in vivo and in vitro. Lab Invest 1984, 50:147-162

18. Sperger JM, Chen X, Draper JS, Antosiewicz JE, Chon CH, Jones SB, Brooks JD, Andrews PW, Brown PO, Thomson JA: Gene expression patterns in human embryonic stem cells and human pluripotent germ cell tumors. Proc Natl Acad Sci USA 2003, 100:13350-13355

19. Eckert D, Nettersheim D, Heukamp LC, Kitazawa S, Biermann K, Schorle H: TCam-2 but not JKT-1 cells resemble seminoma in cell culture. Cell Tissue Res 2008, 331:529-538

20. Weggen S, Eriksen JL, Sagi SA, Pietrzik CU, Ozols V, Fauq A, Golde $\mathrm{TE}, \mathrm{Koo} \mathrm{EH}$ : Evidence that nonsteroidal anti-inflammatory drugs decrease amyloid beta 42 production by direct modulation of gammasecretase activity. J Biol Chem 2003, 278:31831-31837

21. Opitz L, Salinas-Riester G, Grade M, Jung K, Jo P, Emons G, Ghadimi BM, Beissbarth T, Gaedcke J: Impact of RNA degradation on gene expression profiling. BMC Med Genomics 2010, 3:36

22. Igawa T, Lin FF, Lee MS, Karan D, Batra SK, Lin MF: Establishment and characterization of androgen-independent human prostate cancer LNCaP cell model. Prostate 2002, 50:222-235

23. de Jong J, Stoop H, Gillis AJ, van Gurp RJ, van de Geijn GJ, Boer M, Hersmus R, Saunders PT, Anderson RA, Oosterhuis JW, Looijenga LH: Differential expression of SOX17 and SOX2 in germ cells and stem cells has biological and clinical implications. J Pathol 2008 , 215:21-30

24. Van Lint C, Emiliani S, Verdin E: The expression of a small fraction of cellular genes is changed in response to histone hyperacetylation. Gene Expr 1996, 5:245-253

25. Marks PA, Richon VM, Rifkind RA: Histone deacetylase inhibitors: inducers of differentiation or apoptosis of transformed cells. J Natl Cancer Inst 2000, 92:1210-1216

26. Phiel CJ, Zhang F, Huang EY, Guenther MG, Lazar MA, Klein PS: Histone deacetylase is a direct target of valproic acid, a potent anticonvulsant, mood stabilizer, and teratogen. J Biol Chem 2001 276:36734-36741

27. Han JW, Ahn SH, Park SH, Wang SY, Bae GU, Seo DW, Kwon HK, Hong S, Lee HY, Lee YW, Lee HW: Apicidin, a histone deacetylase inhibitor, inhibits proliferation of tumor cells via induction of p21WAF1/ Cip1 and gelsolin. Cancer Res 2000, 60:6068-6074

28. Brodie MJ, Dichter MA: Antiepileptic drugs. N Engl J Med 1996, 334:168-175

29. Yang Y, Turner RS, Gaut JR: The chaperone BiP/GRP78 binds to amyloid precursor protein and decreases Abeta40 and Abeta42 secretion. J Biol Chem 1998, 273:25552-25555

30. Kudo T, Okumura M, Imaizumi K, Araki W, Morihara T, Tanimukai H, Kamagata E, Tabuchi N, Kimura R, Kanayama D, Fukumori A, Tagami S, Okochi M, Kubo M, Tanii H, Tohyama M, Tabira T, Takeda M: Altered localization of amyloid precursor protein under endoplasmic reticulum stress. Biochem Biophys Res Commun 2006, 344:525-530

31. Hoshino T, Nakaya T, Araki W, Suzuki K, Suzuki T, Mizushima T: Endoplasmic reticulum chaperones inhibit the production of amyloidbeta peptides. Biochem J 2007, 402:581-589

32. Bai Y, Markham K, Chen F, Weerasekera R, Watts J, Horne P, Wakutani Y, Bagshaw R, Mathews PM, Fraser PE, Westaway D, St. George-Hyslop P, Schmitt-UIms G: The in vivo brain interactome of the amyloid precursor protein. Mol Cell Proteomics 2008, 7:15-34

33. Satoh M, Nakai A, Sokawa Y, Hirayoshi K, Nagata K: Modulation of the phosphorylation of glucose-regulated protein, GRP78, by transformation and inhibition of glycosylation. Exp Cell Res 1993, 205: 76-83

34. Skotheim RI, Lind GE, Monni O, Nesland JM, Abeler VM, Fossa SD, Duale N, Brunborg G, Kallioniemi O, Andrews PW, Lothe RA: Differentiation of human embryonal carcinomas in vitro and in vivo reveals expression profiles relevant to normal development. Cancer Res 2005, 65:5588-5598

35. Korkola JE, Houldsworth J, Dobrzynski D, Olshen AB, Reuter VE, Bosl GJ, Chaganti RS: Gene expression-based classification of nonseminomatous male germ cell tumors. Oncogene 2005, 24:5101-5107
36. Blaheta RA, Cinatl J Jr: Anti-tumor mechanisms of valproate: a novel role for an old drug. Med Res Rev 2002, 22:492-511

37. Baldassarre G, Romano A, Armenante F, Rambaldi M, Paoletti I, Sandomenico C, Pepe S, Staibano S, Salvatore G, De Rosa G, Persico MG, Viglietto G: Expression of teratocarcinoma-derived growth factor-1 (TDGF-1) in testis germ cell tumors and its effects on growth and differentiation of embryonal carcinoma cell line NTERA2/ D1. Oncogene 1997, 15:927-936

38. Maerz WJ, Baselga J, Reuter VE, Mellado B, Myers ML, Bosl GJ, Spinella MJ, Dmitrovsky E: FGF4 dissociates anti-tumorigenic from differentiation signals of retinoic acid in human embryonal carcinomas. Oncogene 1998, 17:761-767

39. Pietrzik CU, Hoffmann J, Stober K, Chen CY, Bauer C, Otero DA, Roch JM, Herzog V: From differentiation to proliferation: the secretory amyloid precursor protein as a local mediator of growth in thyroid epithelial cells. Proc Natl Acad Sci USA 1998, 95:1770-1775

40. Meng JY, Kataoka H, Itoh H, Koono M: Amyloid beta protein precursor is involved in the growth of human colon carcinoma cell in vitro and in vivo. Int $\mathrm{J}$ Cancer 2001, 92:31-39

41. Caille I, Allinquant B, Dupont E, Bouillot C, Langer A, Muller U, Prochiantz A: Soluble form of amyloid precursor protein regulates proliferation of progenitors in the adult subventricular zone. Development 2004, 131:2173-2181

42. Ko SY, Lin SC, Chang KW, Wong YK, Liu CJ, Chi CW, Liu TY: Increased expression of amyloid precursor protein in oral squamous cell carcinoma. Int J Cancer 2004, 111:727-732

43. Botelho MG, Wang X, Arndt-Jovin DJ, Becker D, Jovin TM: Induction of terminal differentiation in melanoma cells on downregulation of beta-amyloid precursor protein. J Invest Dermatol 2010, 130:14001410

44. Takayama K, Tsutsumi S, Suzuki T, Horie-Inoue K, Ikeda K, Kaneshiro K, Fujimura T, Kumagai J, Urano T, Sakaki Y, Shirahige K, Sasano H, Takahashi S, Kitamura T, Ouchi Y, Aburatani H, Inoue S: Amyloid precursor protein is a primary androgen target gene that promotes prostate cancer growth. Cancer Res 2009, 69:137-142

45. Baldus CD, Liyanarachchi S, Mrozek K, Auer H, Tanner SM, Guimond M, Ruppert AS, Mohamed N, Davuluri RV, Caligiuri MA, Bloomfield $\mathrm{CD}$, de la Chapelle A: Acute myeloid leukemia with complex karyotypes and abnormal chromosome 21: amplification discloses overexpression of APP, ETS2, and ERG genes. Proc Natl Acad Sci USA 2004, 101:3915-3920

46. Maesako Y, Uchiyama T, Ohno H: Comparison of gene expression profiles of lymphoma cell lines from transformed follicular lymphoma, Burkitt's lymphoma and de novo diffuse large B-cell lymphoma. Cancer Sci 2003, 94:774-781

47. Krause K, Karger S, Sheu SY, Aigner T, Kursawe R, Gimm O, Schmid $\mathrm{KW}$, Dralle H, Fuhrer D: Evidence for a role of the amyloid precursor protein in thyroid carcinogenesis. J Endocrinol 2008, 198:291-299

48. Haven CJ, Howell VM, Eilers PH, Dunne R, Takahashi M, van Puijenbroek M, Furge K, Kievit J, Tan MH, Fleuren GJ, Robinson BG, Delbridge LW, Philips J, Nelson AE, Krause U, Dralle H, Hoang-Vu C Gimm O, Morreau H, Marsh DJ, Teh BT: Gene expression of parathyroid tumors: molecular subclassification and identification of the potential malignant phenotype. Cancer Res 2004, 64:7405-7411

49. Tang CE, Guan YJ, Yi B, Li XH, Liang K, Zou HY, Yi H, Li MY, Zhang PF, Li C, Peng F, Chen ZC, Yao KT, Xiao ZQ: Identification of the amyloid beta-protein precursor and cystatin $\mathrm{C}$ as novel epidermal growth factor receptor regulated secretory proteins in nasopharyngeal carcinoma by proteomics. J Proteome Res 2010, 9:6101-6111

50. Przyborski SA: Differentiation of human embryonic stem cells after transplantation in immune-deficient mice. Stem Cells 2005, 23:12421250

51. Guo Q, Robinson N, Mattson MP: Secreted beta-amyloid precursor protein counteracts the proapoptotic action of mutant presenilin-1 by activation of NF-kappaB and stabilization of calcium homeostasis. J Biol Chem 1998, 273:12341-12351

52. Copanaki E, Chang S, Vlachos A, Tschape JA, Muller UC, Kogel D, Deller T: sAPPalpha antagonizes dendritic degeneration and neuron death triggered by proteasomal stress. Mol Cell Neurosci 2010, 44: 386-393

53. Porayette P, Gallego MJ, Kaltcheva MM, Meethal SV, Atwood CS: Amyloid-beta precursor protein expression and modulation in human embryonic stem cells: a novel role for human chorionic gonadotropin. Biochem Biophys Res Commun 2007, 364:522-527 
54. Gottlicher M, Minucci S, Zhu P, Kramer OH, Schimpf A, Giavara S, Sleeman JP, Lo Coco F, Nervi C, Pelicci PG, Heinzel T: Valproic acid defines a novel class of HDAC inhibitors inducing differentiation of transformed cells. EMBO J 2001, 20:6969-6978

55. Liu T, Kuljaca S, Tee A, Marshall GM: Histone deacetylase inhibitors: multifunctional anticancer agents. Cancer Treat Rev 2006, 32:157-165

56. Wu J, Kaufman RJ: From acute ER stress to physiological roles of the unfolded protein response. Cell Death Differ 2006, 13:374-384

57. Muresan Z, Arvan P: Enhanced binding to the molecular chaperone BiP slows thyroglobulin export from the endoplasmic reticulum. Mol Endocrinol 1998, 12:458-467

58. Qiu W, Kohen-Avramoglu R, Mhapsekar S, Tsai J, Austin RC, Adeli K: Glucosamine-induced endoplasmic reticulum stress promotes ApoB100 degradation: evidence for Grp78-mediated targeting to proteasomal degradation. Arterioscler Thromb Vasc Biol 2005, 25: $571-577$

59. Baumeister $P$, Dong D, Fu Y, Lee AS: Transcriptional induction of GRP78/BiP by histone deacetylase inhibitors and resistance to histone deacetylase inhibitor-induced apoptosis. Mol Cancer Ther 2009 , 8:1086-1094

60. Steinhilb ML, Turner RS, Gaut JR: The protease inhibitor, MG132, blocks maturation of the amyloid precursor protein Swedish mutant preventing cleavage by beta-Secretase. J Biol Chem 2001, 276: 4476-4484

61. Wiest DL, Burkhardt JK, Hester S, Hortsch M, Meyer DI, Argon Y: Membrane biogenesis during $\mathrm{B}$ cell differentiation: most endoplasmic reticulum proteins are expressed coordinately. J Cell Biol 1990, 110:1501-1511

62. Huo R, Zhu YF, Ma X, Lin M, Zhou ZM, Sha JH: Differential expression of glucose-regulated protein 78 during spermatogenesis. Cell Tissue Res 2004, 316:359-367

63. Nakanishi K, Sudo T, Morishima N: Endoplasmic reticulum stress signaling transmitted by ATF6 mediates apoptosis during muscle development. J Cell Biol 2005, 169:555-560

64. Chiellini C, Cochet O, Negroni L, Samson M, Poggi M, Ailhaud G, Alessi MC, Dani C, Amri EZ: Characterization of human mesenchymal stem cell secretome at early steps of adipocyte and osteoblast differentiation. BMC Mol Biol 2008, 9:26

65. Sugiura K, Muro Y, Futamura K, Matsumoto K, Hashimoto N, Nishizawa Y, Nagasaka T, Saito H, Tomita Y, Usukura J: The unfolded protein response is activated in differentiating epidermal keratinocytes. J Invest Dermatol 2009, 129:2126-2135

66. Khan N, Jeffers M, Kumar S, Hackett C, Boldog F, Khramtsov N, Qian X, Mills E, Berghs SC, Carey N, Finn PW, Collins LS, Tumber A, Ritchie JW, Jensen PB, Lichenstein HS, Sehested M: Determination of the class and isoform selectivity of small-molecule histone deacetylase inhibitors. Biochem J 2008, 409:581-589

67. Xia Q, Sung J, Chowdhury W, Chen CL, Hoti N, Shabbeer S, Carducci M, Rodriguez R: Chronic administration of valproic acid inhibits prostate cancer cell growth in vitro and in vivo. Cancer Res 2006, 66: 7237-7244

68. Jones J, Juengel E, Mickuckyte A, Hudak L, Wedel S, Jonas D, Blaheta RA: The histone deacetylase inhibitor valproic acid alters growth properties of renal cell carcinoma in vitro and in vivo. $\mathrm{J}$ Cell Mol Med 2009, 13:2376-2385

69. Ecke I, Petry F, Rosenberger A, Tauber S, Monkemeyer S, Hess I, Dullin C, Kimmina S, Pirngruber J, Johnsen SA, Uhmann A, Nitzki F, Wojnowski L, Schulz-Schaeffer W, Witt O, Hahn H: Antitumor effects of a combined 5-aza-2' deoxycytidine and valproic acid treatment on rhabdomyosarcoma and medulloblastoma in Ptch mutant mice. Cancer Res 2009, 69:887-895

70. Wishnow KI, Johnson DE, Swanson DA, Tenney DM, Babaian RJ, Dunphy $\mathrm{CH}$, Ayala AG, Ro JY, von Eschenbach AC: Identifying patients with low-risk clinical stage I nonseminomatous testicular tumors who should be treated by surveillance. Urology 1989, 34:339_ 343

71. Moul JW, McCarthy WF, Fernandez EB, Sesterhenn IA: Percentage of embryonal carcinoma and of vascular invasion predicts pathological stage in clinical stage I nonseminomatous testicular cancer. Cancer Res 1994, 54:362-364 